NBSIR 84-2847(R)

\title{
National Bureau of Standards Response to the 1982 National Measurement Requirements Survey of the NCSL National Measurement Requirements Committee
}

U.S. DEPARTMENT OF COMMERCE

National Bureau of Standards

National Measurement Laboratory

Office of Physical Measurement Services

Washington, DC 20234

March 1984

Prepared for

U.S. DEPARTMENT OF COMMERCE

National Bureau of Standards

Washington, DC 20234 

NATIONAL BUREAU OF STANDARDS

RESPONSE TO THE 1982 NATIONAL

MEASUREMENT REQUIREMENTS

SURVEY OF THE NCSL NATIONAL

MEASUREMENT REQUIREMENTS

COMMITTEE

B. C. Belanger

R. K. Kirby

J. D. Simmons

U.S. DEPARTMENT OF COMMERCE

National Bureau of Standards

National Measurement Laboratory

Office of Physical Measurement Services

Washington, DC 20234

March 1984

Prepared for

U.S. DEPARTMENT OF COMMERCE

National Bureau of Standards

Washington, DC 20234

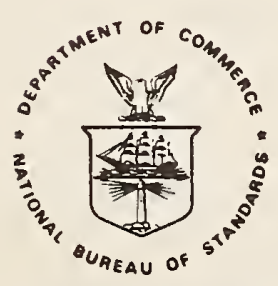

U.S. DEPARTMENT OF COMMERCE, Malcolm Baldrige, Secretary NATIONAL BUREAU OF STANDARDS, Ernest Ambler, Director 



\section{NATIONAL BUREAU OF STANDARDS RESPONSE \\ TO THE}

1982 NATIONAL MEASUREMENT REQUIREMENTS SURVEY

OF THE

NATIONAL MEASUREMENT REQUIREMENTS COMMITTEE

NATIONAL CONFERENCE OF STANDARDS LABORATORIES

Edited by:

B. C. Belanger

R. K. Kirby

J. D. Simmons

Issued March, 1984 



\section{CONTENTS}

Page

Response to Section 2B

dc and Low Frequency Measurement Requirements . . . . . . 4

Response to Section $2 \mathrm{C}$

rf and Microwave Measurement Requirements . . . . . . 13

Response to Section 2D

Electro-optics Measurement Requirements . . . . . . 22

Response to Section $2 E$

Temperature, Pressure, and Related Measurement Services . 29

Response to Section $2 F$

Physical/Mechanical Measurement Requirements . . . . 38

Educational Seminars and Workshops . . . . . . . . . 41 


\section{NBS RESPONSE TO THE \\ 1982 NCSL NATIONAL MEASUREMENT REQUIREMENTS SURVEY}

\section{INTRODUCTION}

This report constitutes the response of the National Bureau of Standards (NBS) to the 1982 National Measurement Requirements Survey Report published by the NCSL's National Measurement Requirements Committee in May 1983.

Information of the kind contained in the Survey Report is extremely useful to NBS in evaluating the effectiveness of ongoing programs and for planning future programs. The Report is particularly important to NBS because of the large number of organizations that have responded and because of the detailed technical requirements identified in the report--quantities to be measured, ranges, and accuracies. NBS is grateful to the National Measurement Requirements Committee (NMRC) of NCSL for their extensive effort in collecting, summarizing, and tabulating the material and to the NCSL members (and nonmembers) who took the time to respond to the questionnaires.

The NCSL NMRC Report represents primarily the viewpoint of the standards laboratory community. NBS and the NMRC recognize that there are other users of NBS measurement services whose requirements may not be communicated to the standards laboratories that participated in this survey. For example, the views of many users of NBS ionizing radiation measurement services in the medical and health field are not well represented. Also, requirements from classified military programs cannot be included for obvious reasons. In spite of these constraints, NBS believes that the NCSL NMRC Report is one of the most comprehensive sources of technical requirements information for measurement services currently available.

The Report could have been even more useful had it contained more economic analysis and data that would permit NBS to evaluate the relative importance of the requested measurements to industrial productivity and quality control. NBS recognizes the difficulty of developing quantitative economic data and anecdotal material and encourages continued efforts to collect such data. In addition, in the continuing effort of NCSL to keep NBS aware of measurement requirements an attempt should be made to provide a prioritized list from each of the NMRC subcommittees that is ordered according to their perceived need.

The needs for expanded NBS services will probably always exceed the resources available to NBS for responding to those needs. Accordingly, NBS must set priorities carefully to ensure that resources are allocated to those measurement areas that are currently most important to the country. Since needs change as technology changes, some services will be closed while other new services are started. Because of the long lead times that are typically required to develop new calibration services and the high cost of research and development in new measurement areas, decisions to develop new services cannot be made without careful justification. The National Measurement Requirements Survey Report provides critically important information for project justification and priority decisions.

The subcommittees involved in the preparation of the Survey Report generally worked closely with the corresponding technical groups responsible 
for NBS calibration services. In some cases information concerning the current status of NBS services and future plans was incorporated directly into the Survey Report. In such cases, this document includes only material deemed necessary to clarify or expand on the information in the NMRC Report or to cover those requirements for which NBS' current status and plans were not addressed. The format for the presentation of the material in the NMRC Report also varies from section to section. Each section in this report is labeled to correspond with the relevant section in the NMRC Report.

Some respondents to the NCSL questionnaire indicated that they were not aware of existing NBS services. NBS Special Publication 250, "Calibration and Related Measurement Services of the National Bureau of Standards" describes NBS' services and is updated every two years. The next edition of SP 250 will be issued in late 1984. An Appendix to SP 250 giving current prices and recent changes in services is published every 6 months. These publications are provided to anyone interested in using NBS services. Persons not already on the mailing list who wish to receive these publications should contact:

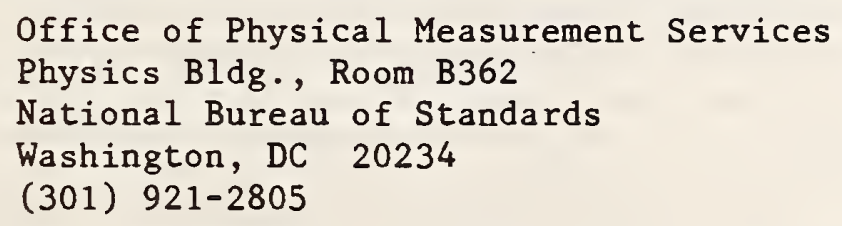

For certain types of measurements, NBS Standard Reference Materials are a more convenient method of obtaining traceability to NBS. For information on Standard Reference Materials contact:

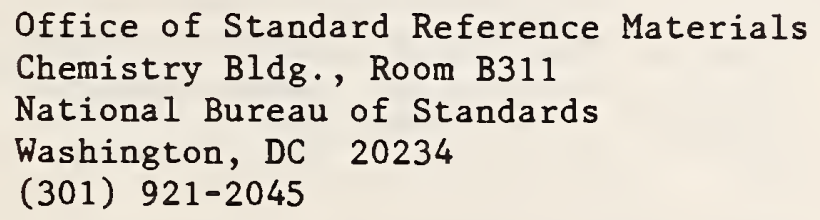

In some cases, services that are not listed explicitly in SP 250 can be performed by NBS on a special test basis. Before concluding that NBS does not provide a particular service, the Office of Physical Measurement Services or appropriate NBS line managers should be contacted to see whether or not a special test can be arranged. 


\section{RESPONSE TO SECTION 2B \\ DC AND LOW FREQUENCY MEASUREMENT REQUIREMENTS}

\section{INTRODUCTION}

The responsibility for providing calibration services and for carrying out research and development in dc/lf electrical measurements falls within two different Centers at NBS. The Electricity Division of the Center for Basic Standards (CBS) is responsible for dc voltage, impedance, ac-dc difference and resistance, whereas the Electrosystems Division of the Center for Electronics and Electrical Engineering (CEEE) is responsible for phase angle, power and energy measurements, and high voltage measurements.

Since the termination of the magnetic calibration services at NBS several years ago, no NBS group has carried out work in this area directed towards calibration services. The CEEE, however, has been surveying the field to determine whether there is sufficient justification for establishing a new magnetic measurements program at NBS. The Electricity Division also has expertise in magnetic measurements and is following this survey with interest. If the survey results and other considerations support a decision to reestablish magnetic measurement services, NBS will be in a position to draw on expertise in both centers (see Section on Magnetic Field Strength below).

The NCSL NMRC Report describes the general state of affairs in the metrology community and the needs expressed in it represent a wide range of opportunities for future NBS activity. In some cases, however, the accuracy requirements indicated in the NCSL Report are more stringent than those identified to NBS previously; e.g., the requirement for phase angle uncertainty in the NCSL Report is \pm 0.001 degree, other inputs had indicated an uncertainty requirement no better than \pm 0.005 degree. Also, NBS has received requests for dc/lf measurement services through other channels in addition to those indicated by the respondents to the NCSL Survey.

GENERAL COMMENTS ON NBS PRIORITIES AND PLANS

NBS Contact: Norman B. Belecki (301) 921-2715

The highest priorities in this area are to continue to maintain services related to fundamental standards with the highest level of quality; to reduce turnaround time in those services where there is room for improvement; to reinstate previously curtailed services in the resistance area; and to document the technology and procedures used to deliver existing services. The second priorities are to expand existing services and to initiate new services as indicated in this study and by the various members of the metrology community. These include:

a) Developing a calibration capability for capacitance dissipation factor;

b) Extending the ranges of measurement and applied frequency for the impedance calibration services;

c) Providing a calibration service for ac resistors at frequencies up to $100 \mathrm{kHz}$; 
d) Developing a MAP procedure for alternating voltage and current measurements; and

e) Developing a MAP for dc voltage sources at the $10 \mathrm{~V}$ level.

At present resource levels, services in these latter areas will not be available for several years.

NBS has increased the staff in this dc/If area by two professionals and one technician. The first assignment of the professionals will be to automate the calibration of thermal current and voltage converters. This effort is expected to reduce the backlog of work in this key area and to allow some improvement in our measurement uncertainties. The second assignment of the professionals will be in the impedance area.

The new technician should allow the restoration of services for odddecade value resistance standards. Calibration of resistors at the teraohm level and higher is also expected to be resumed when an automated capacitive discharge system for making the measurements is completed. Several publications covering measurement techniques in the voltage and resistance areas will be prepared.

NBS also assigns a high priority to maintaining reference standards and providing calibration services for electrical power, energy, and phase angle. In the Power/Energy area, existing services will be upgraded by increasing the accuracy and the range of quantities that are currently measured. The calibration service for phase angle, now provided on a special test basis up to 5 $\mathrm{kHz}$, is expected to become a regularly-offered calibraition service for frequencies up to $50 \mathrm{kHz}$. Work is underway with existing funding to accomplish this upgrade. These plans will permit NBS to address the principal needs indicated in the NCSL survey in a time span of about 3-5 years. Without additional funding, however, all of the needs indicated in the NCSL survey cannot be fully met; e.g., phase angle uncertainty within \pm 0.001 degree. As our plans are responsive to the needs of the users, no major modifications of these plans are necessary, only the funding to carry them out in a timely fashion. 


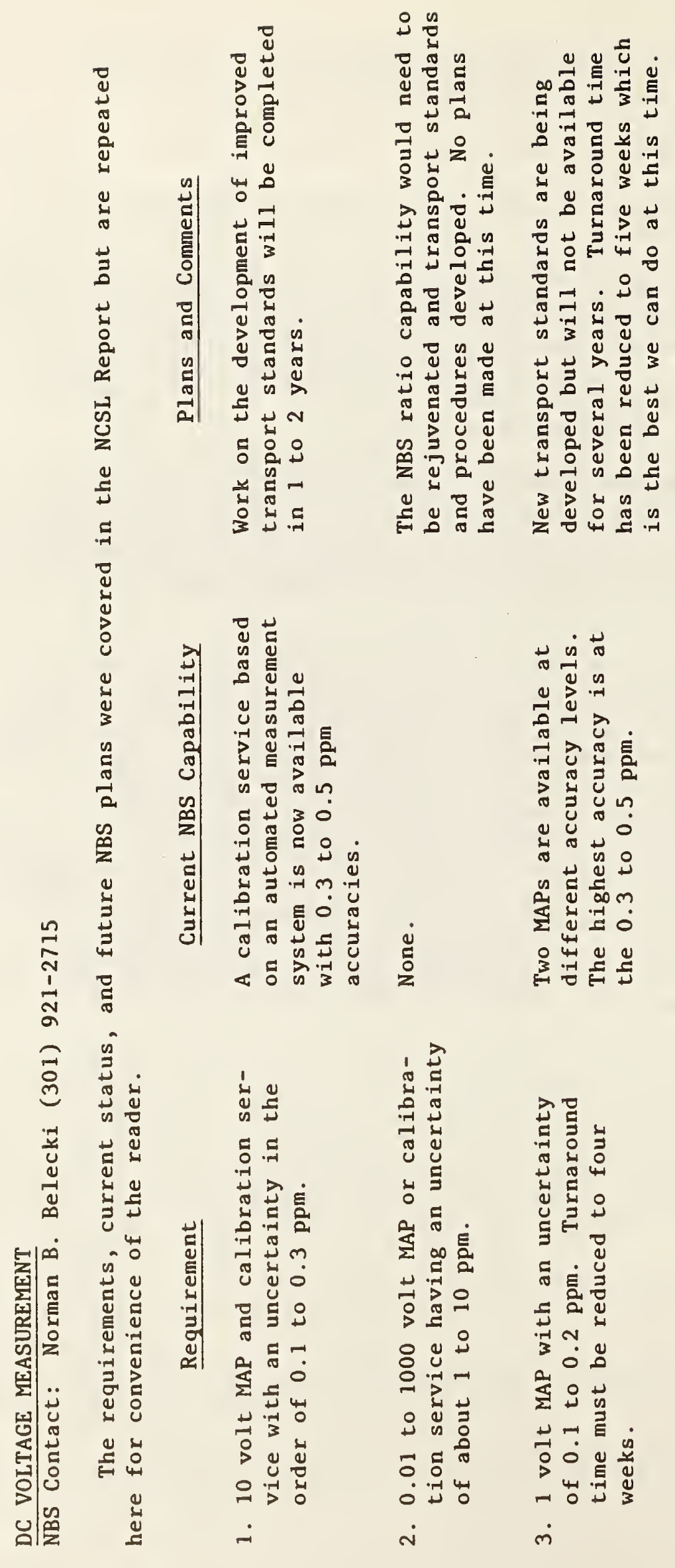




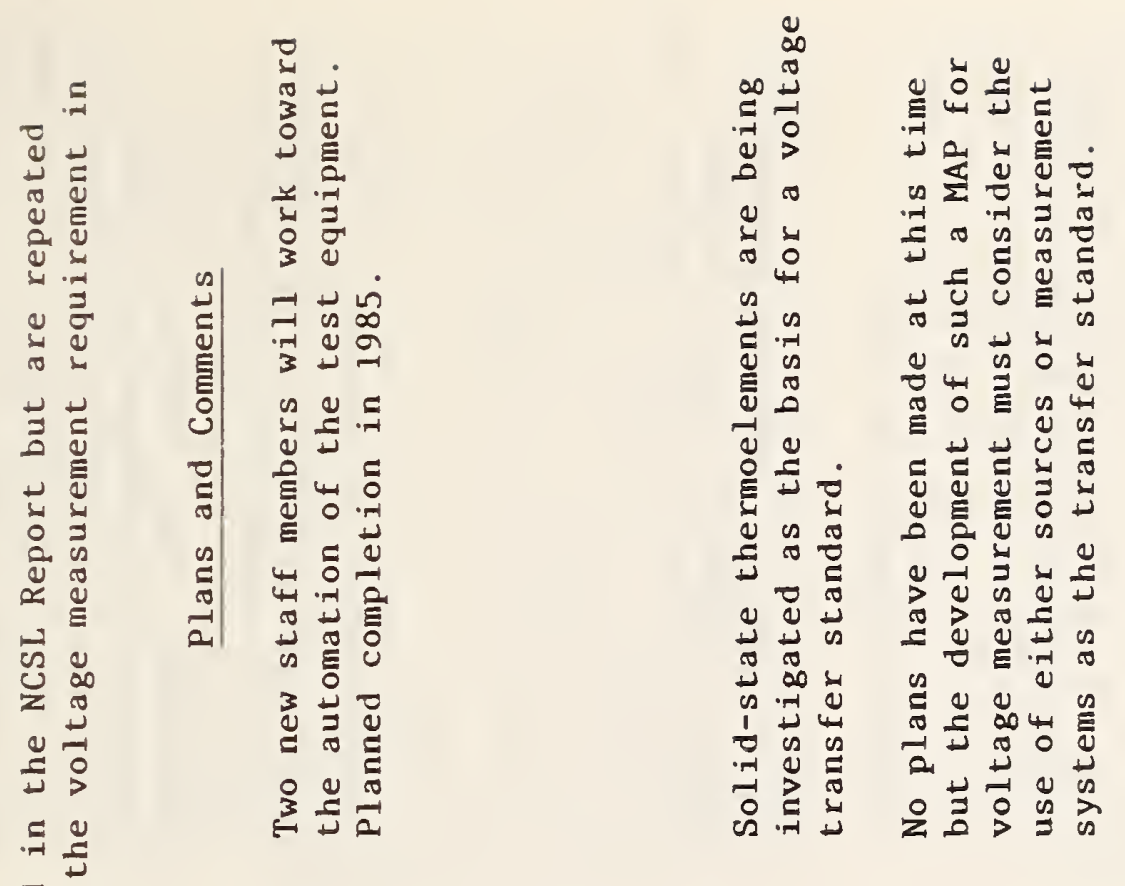

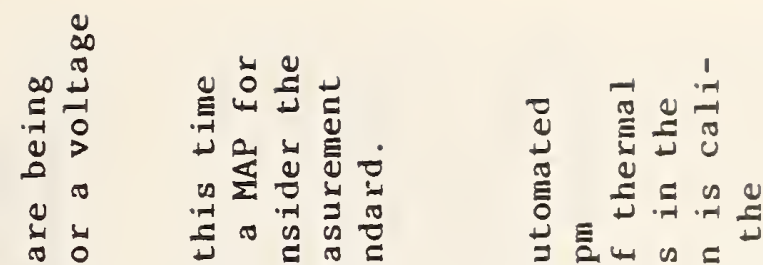

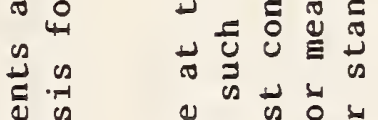

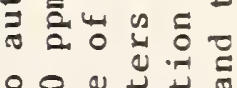

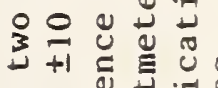

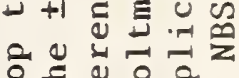

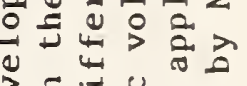

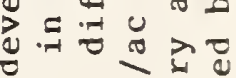

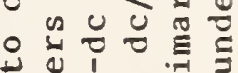
บ 0 율 क ज

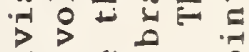
-

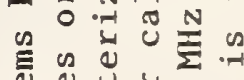

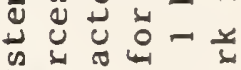

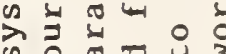
क

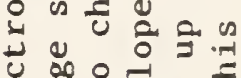
U ज्ञ

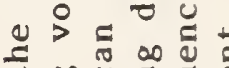
- $\infty$ U 율

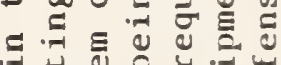
तथ 3 प कि U य E एँ $\exists$ कह

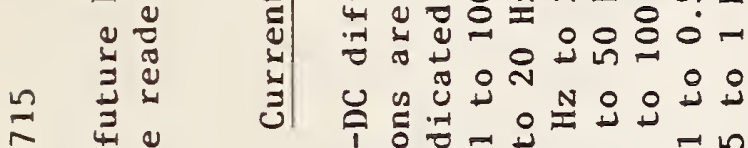

กิ क ज च 令 के

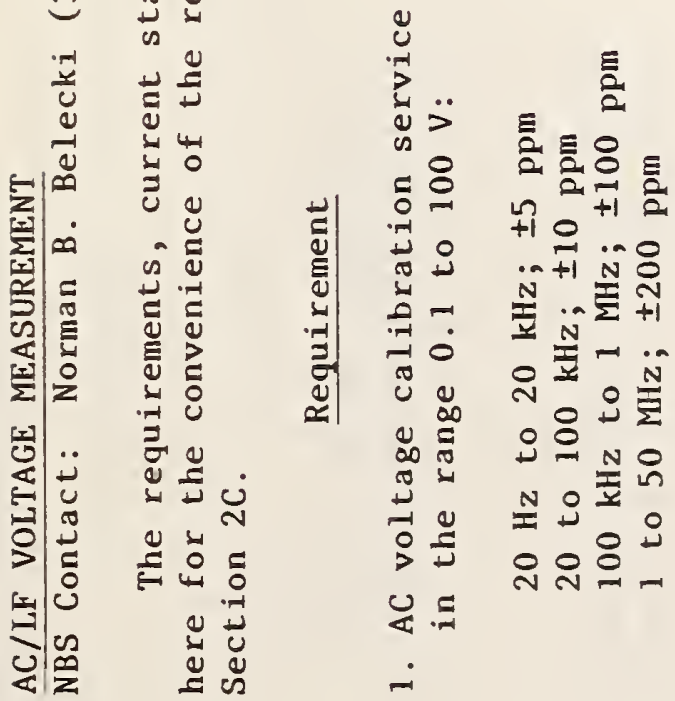

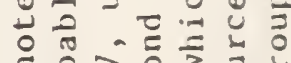

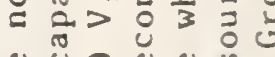

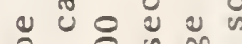

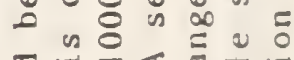
- 데

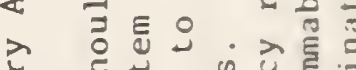
的牙 $\Rightarrow$ iे क जे c $\infty$ a u ฮร

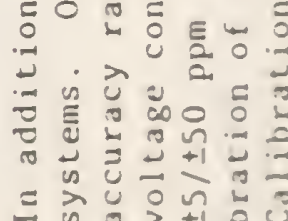




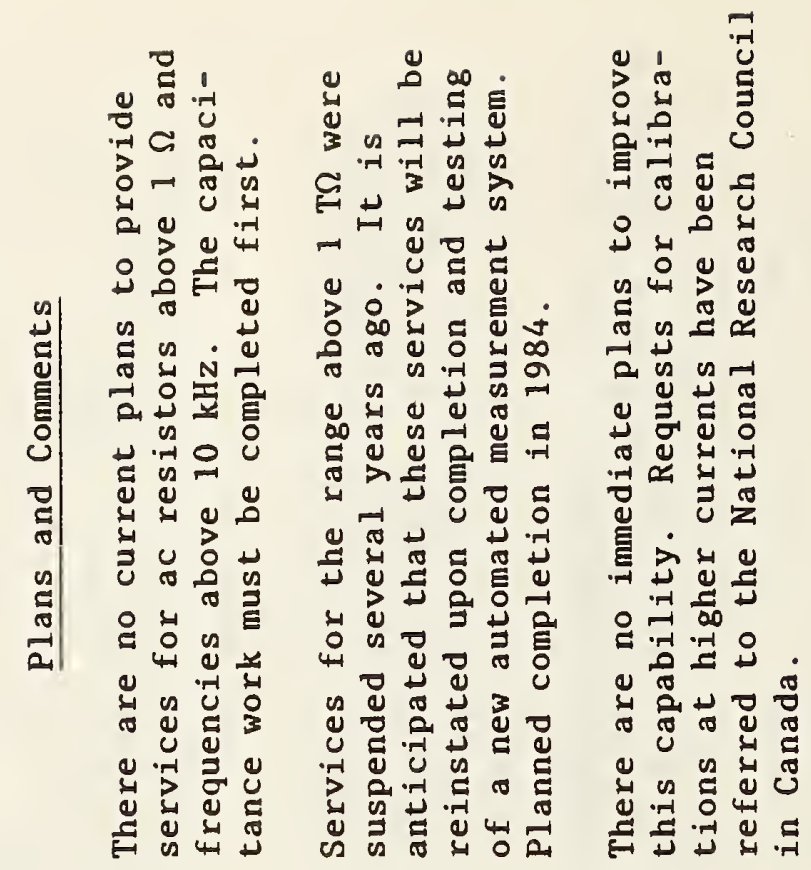

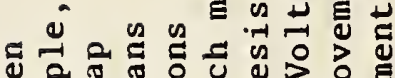
ปึ.

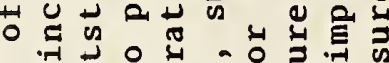
( ) त्र

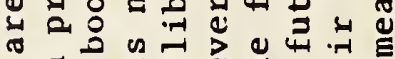

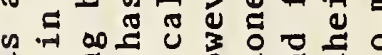

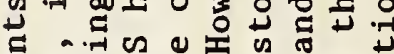

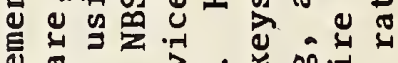

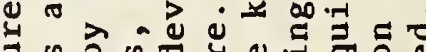
ปี ถิ

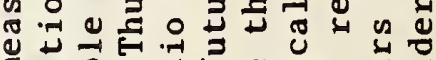

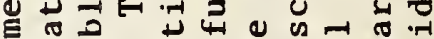

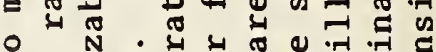

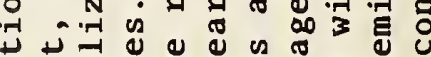

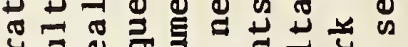

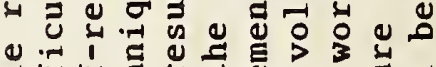

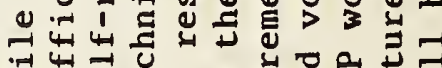

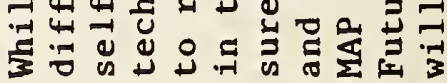

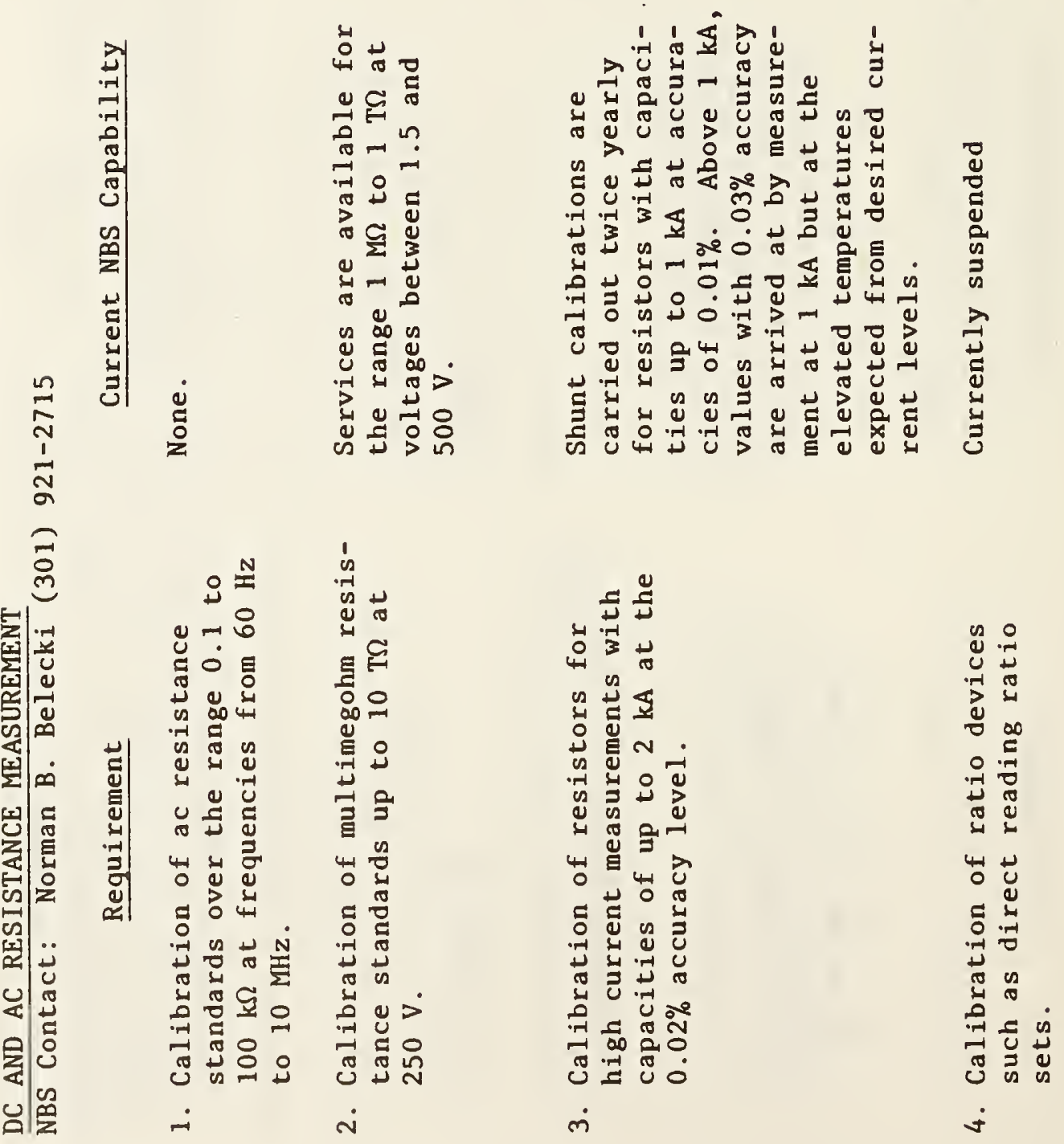




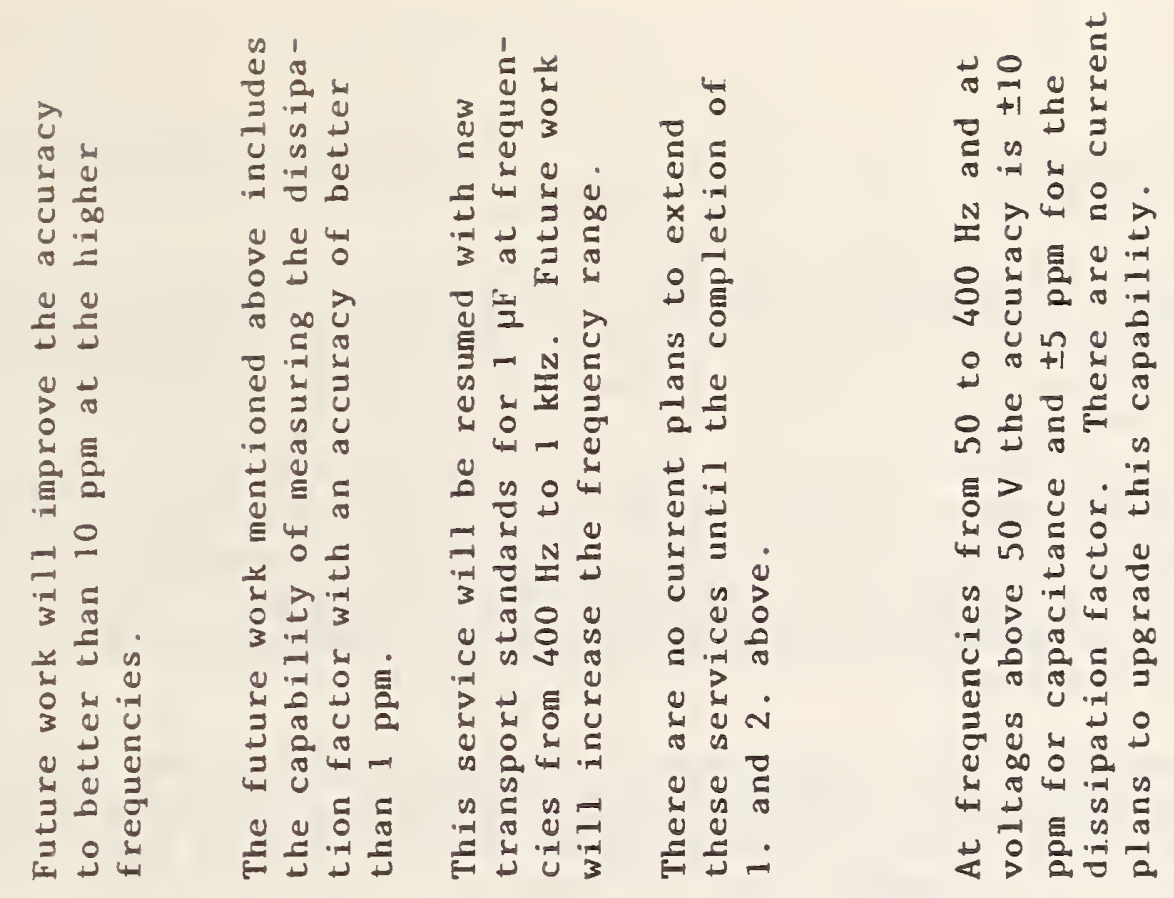

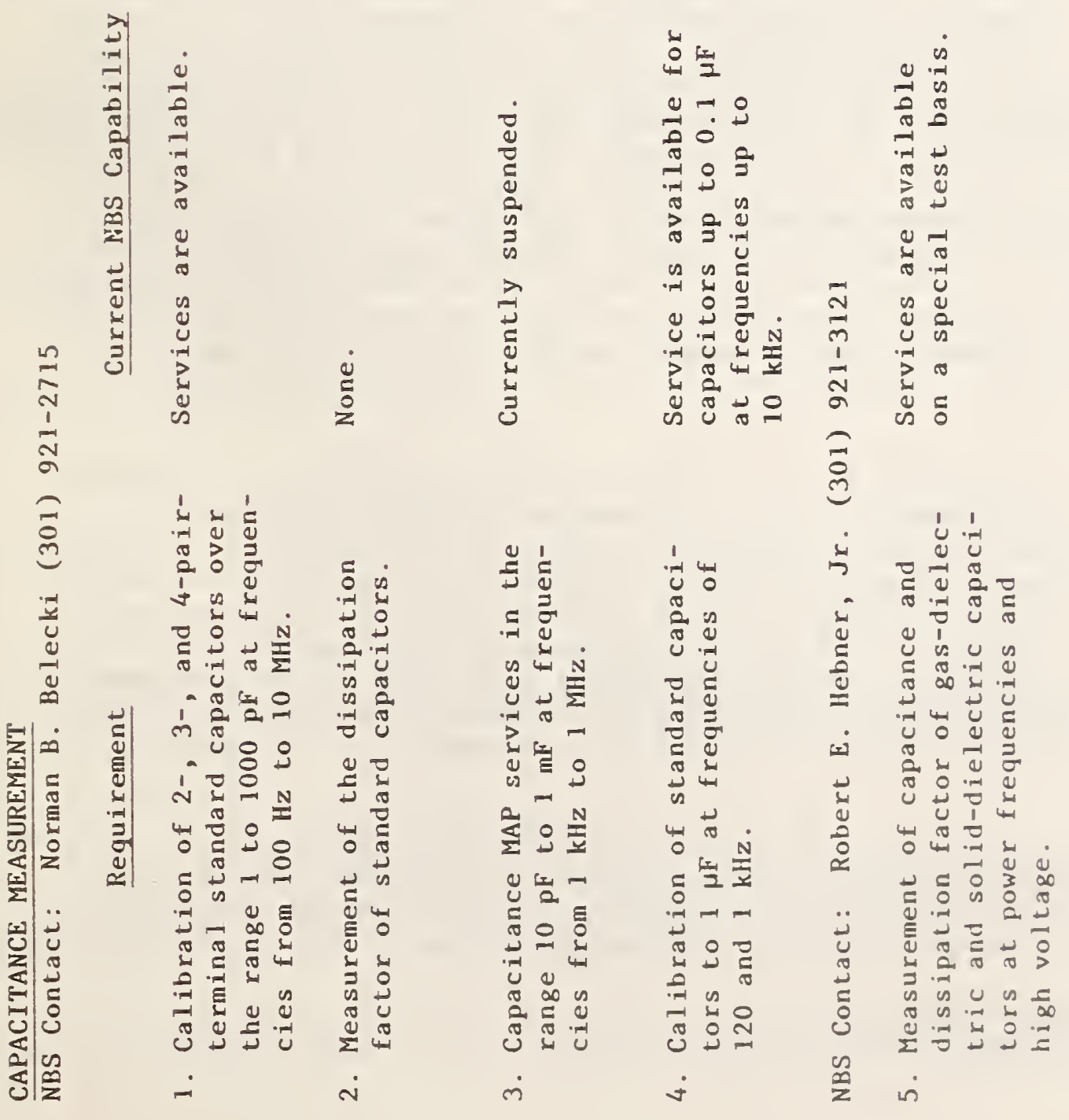


The information presented in the Report regarding calibration needs in the area of magnetics is consistent with information we have gathered in a preliminary assessment of the field. Prior to the survey on magnetics service, NBS had identified a relatively small number of organizations in need of this type of magnetic calibration service. However, our investigation has shown that need for the service is likely to increase significantly in the near future as pointed out in the Report. This is due in large part to the increased use of nuclear magnetic resonance techniques in medicine and to the introduction into commerce of new magnetic materials such as soft amorphous magnetic alloys and the NdFe hard ferromagnets.

It should be pointed out that there are magnetic measurement areas not addressed by the NCSL survey, such as magnetic recording media and other computer-related fields, that are quite active and in which we have found a significant interest in standards and calibration.

The extent of the need and/or desire of industry and other government agencies for a magnetics service by NBS has been assessed in part by CEEE through numerous contacts with representatives of industry and of the industrial standards-setting organizations. Results are being analyzed from an extensive survey questionnaire mailed to about 2,000 individuals, including members of the IEEE Magnetics Society, ASTM Committee A-6 on Magnetic Properties, and the Magnetic Materials Producers Association. The results of this survey, in conjunction with other input and financial considerations, will determine the future direction of our magnetics work. NBS cannot operate a viable calibration facility unless it is based on a strong state-of-the-art research program in the field. Thus, our first priority is to determine if sufficient interest exists to support creation of a magnetics program which would involve basic research and development of magnetic metrology as well as the creation of additional Standard Reference Materials and, possibly, calibration services.

At the present time CEEE has a capability for making nearly all conventional magnetic measurements in the Electromagnetic Technology Division in Boulder. Operating equipment includes: fluxmeters and gaussmeters of various sorts that can measure flux densities from less than a microtesla to greater than ten tesla (field strengths from 0.8 to $8,000,000 \mathrm{~A} / \mathrm{m}$ ); vibrating sample, ac induction and cryogenic (SQUID) magnetometers for measurement of susceptibility and permeability over the temperature range from $4 \mathrm{~K}$ to room temperature; and superconducting and normal magnetic systems with fields to $9.5 \mathrm{MA} / \mathrm{m}$. None of these systems are now configured or calibrated for true standards work.

The Electricity Division of CBS has the expertise and some of the required apparatus to carry out magnetic field strength calibrations with the highest possible accuracies achievable, especially at low field levels, but there is no plan at this time to reinstate a calibration service. 
NBS Contact: Robert E. Hebner, Jr. (301) 921-3121

Current transformers in the power frequency range are calibrated by the Electrosystems Division on a routine basis. Calibration of ac shunts at power and audio frequencies is performed on a special-test basis in the range of 1 to $100 \mathrm{~m} \Omega$.

Funding has been obtained to develop a capability to evaluate shunts and current transformers used to measure welding currents. This application requires the measurement of current pulses with amplitudes up to $100 \mathrm{kA}$ and durations of tens to hundreds of milliseconds. Development of a bridge for calibrating shunts down to $0.1 \mathrm{~m} \Omega$ and up to frequencies of $100 \mathrm{kHz}$ is progressing slowly with the present funding level.

Long range plans include support of dc current measurements from 5 to $2000 \mathrm{~A}$ as a step toward developing support for dc revenue metering in high voltage dc systems.

\section{POWER AND ENERGY MEASUREMENT}

NBS Contact: Robert E. Hebner, Jr. (301) 921-3121

NBS' present capabilities for power and energy calibration are restricted to power frequencies, 50 to $400 \mathrm{~Hz}$, with a routine uncertainty of $\pm 0.05 \%$.

Under special conditions, we are able to achieve uncertainties in the range \pm 0.01 to $\pm 0.02 \%$. These capabilities are for unity and 0.5 power factor, but no measurements at zero power factor and no VAR's.

At the present time we meet most (but not all) of the calibration requirements of our clients. Present plans are to gradually upgrade this facility during the next 5 years.

The goal is to develop a largely automated facility having the following characteristics:

Frequency : $40 \mathrm{~Hz}$ to $10 \mathrm{kHz}$

Voltage : 10 to $240 \mathrm{~V}$

Current : $10 \mathrm{~mA}$ to $10 \mathrm{~A}$

Power Factor: all, zero to unity, positive and negative

PHASE ANGLE MEASUREMENT

NBS Contact: Barry A. Bell (301) 921-2727

Phase angle calibration up to $5 \mathrm{kHz}$ is presently provided on a trial basis as a special test. After experience is gained and documentation completed, 
it is intended to offer this as a regular calibration service. $R \& D$ is underway on the higher frequency standard that will permit the extension of this service to $50 \mathrm{kHz}$. This high frequency capability (scheduled to be available on a trial basis by early 1986) is clearly important to support the calibration of Automated Test Equipment (ATE).

The capabilities that we are working toward are:

- Frequency: $10 \mathrm{~Hz}$ to $50 \mathrm{kHz}$

- Source-type standard (2 channel)

- Both channels voltages, balanced or unbalanced; or one channel voltage, the other current

- Sinusoidal signals and those with moderate distortion

- Accuracy: \pm 0.005 degree (best, at low frequencies, balanced signals), \pm 0.02 degree (at high frequencies)

OTHER DC AND LF MEASUREMENT AREAS

\section{FIELDS}

NBS Contact: Robert E. Hebner, Jr. (301) 921-3121

Special measurement services for electric and magnetic fields at dc and power frequencies are available as a result of work funded by the U.S. Department of Energy. These services should be particularly helpful to organizations involved in environmental and health-related investigations. For the measurement of relatively low field strengths, the strategy has been to maintain NBS traceability in the measurement of voltage and current (from which field strengths are derived), and to provide guidance in the construction of the test systems used to calibrate field meters. This approach is summarized in IEEE Standard 644-1979 "IEEE Recommended Practices for the Measurement of Electric and Magnetic Fields from AC Power Lines."

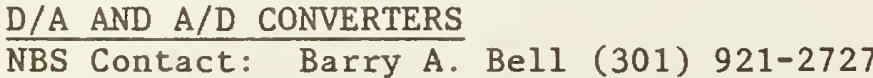

A calibration facility is available at NBS for high resolution data converters ( 12 bits and more). Calibration for static parameters is offered as an existing service; calibration for dynamic parameters is performed on a special test basis. The facility can also be adapted for calibrating certain parameters of DVM's (e.g., their linearity) but additional development funds are required for NBS to establish a regularly offered service. 


\section{RESPONSE TO SECTION 2C \\ RF AND MICROWAVE MEASUREMENT REQUIREMENTS}

Section 2C of the NCSL Report contains a considerable amount of information concerning NBS' currently-offered services and our future plans. Accordingly, this section of this report does not attempt to duplicate that information. Rather, it elaborates on NBS' plans for the measurement requirements identified in the survey report and explains current constraints in more detail.

GENERAL RF AND MICROWAVE METROLOGY

NBS Contact: Cletus A. Hoer (303) 497-3705

The effort to develop and implement automated six-port measurement methods to the point that they can be used to provide NBS measurement services is nearing completion. New management for the Microwave Metrology Group is thus developing plans for the microwave metrology program for the next 5 years with a real opportunity to take up new work. In doing so, our chief sources of guidance are information from the NCSL Measurement Requirements Study, together with comments from our customers and sponsors and other interactions, for example information from the Workshop on Future Needs in Microwave Metrology that we organized at the 1983 IEEE-MTT Symposium in Boston. After some follow-up with the people who proposed new efforts, in order to set priorities, we will have an unusual opportunity to be responsive.

The tasks of immediate urgency are to complete the evaluation of uncertainty, provision for quality control, and the documentation of the 6-port systems and to bring them on line to replace obsolete calibration systems. We must also provide calibration services for attenuation at $1.25 \mathrm{MHz}$ and for standards with $3.5 \mathrm{~mm}$ connectors. We need to complete the documentation of some of the older calibration systems that will remain in service.

Upon completion of these tasks, we will turn our attention to providing more complete calibration coverage of the frequency bands up to $100 \mathrm{GHz}$ (especially filling the gap that presently exists between 40 and $55 \mathrm{GHz}$ ). The timing of requirements above $100 \mathrm{GHz}$ remains nebulous, so our response to those may be given lower priority.

It is clear that calibration of microwave power is needed over a wider dynamic range and with greater accuracy that at present. We intend to respond to this need.

Finally, two general areas to which we will turn our attention are techniques for making measurements of microwave and millimeter-wave integrated circuits on-chip, and the calibration of automated test and measurement systems.

The dates for new services given under the plans and comments column are provided for guidance and are to be taken as our present best estimates of when services will become available. In some cases a service will be offered on an experimental basis at first, to test both the mechanics of providing it and customer response. Rough estimates of the cost of developing a service are provided for some services for which funding is uncertain to provide some feeling for the support required. Priorities can be shifted, or projects can be accelerated, if the need is great enough for other government agencies to provide additional funding. 


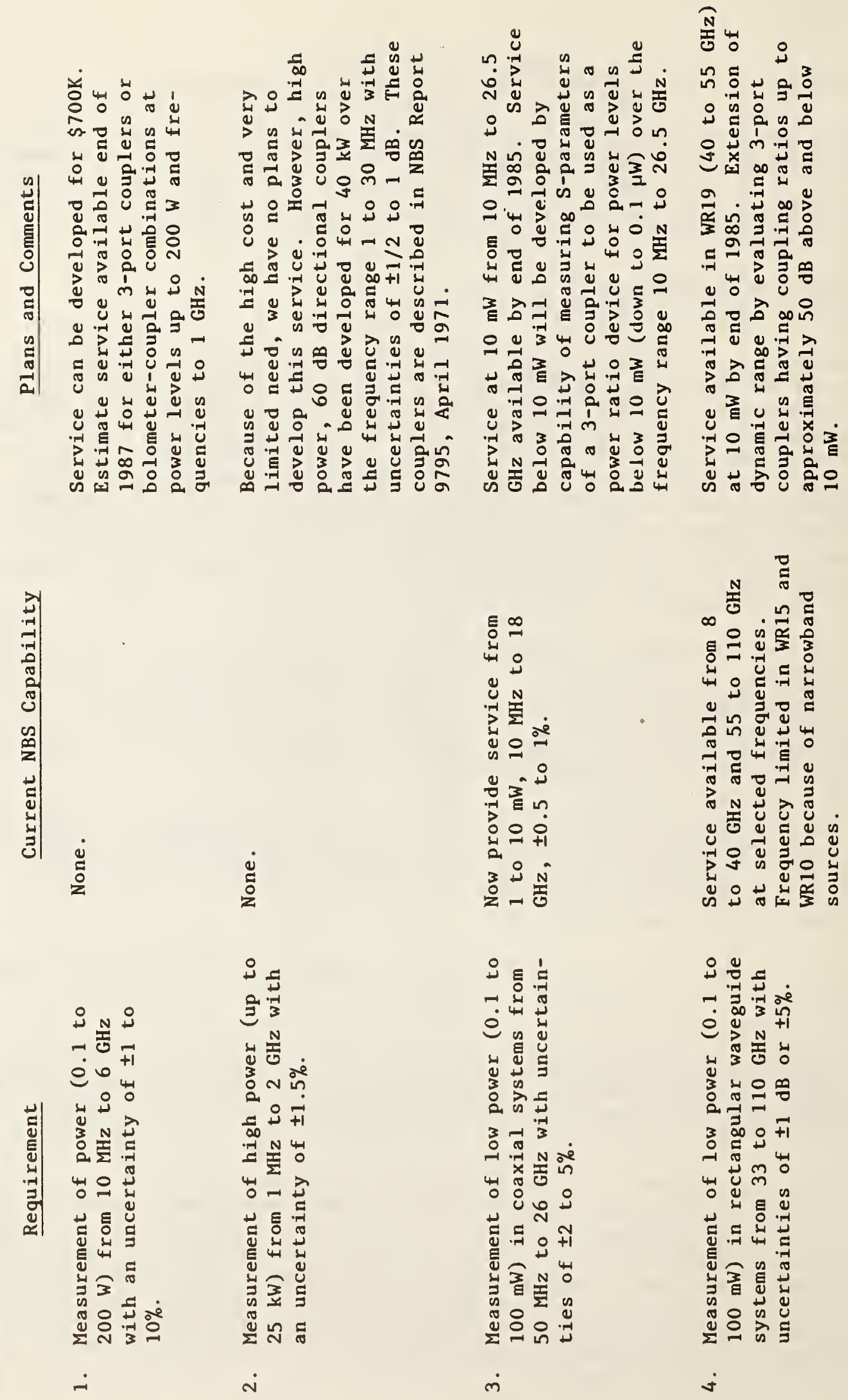




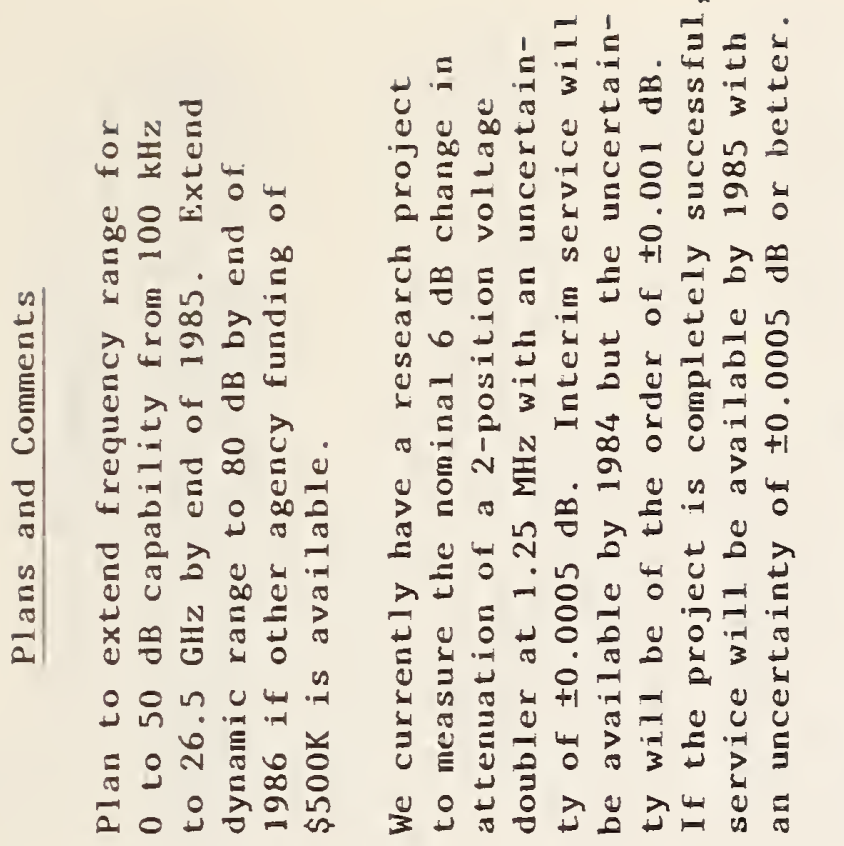

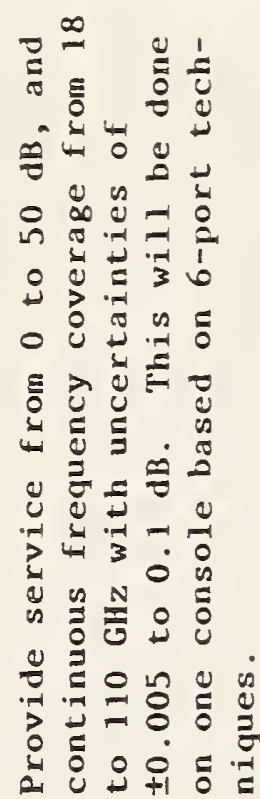

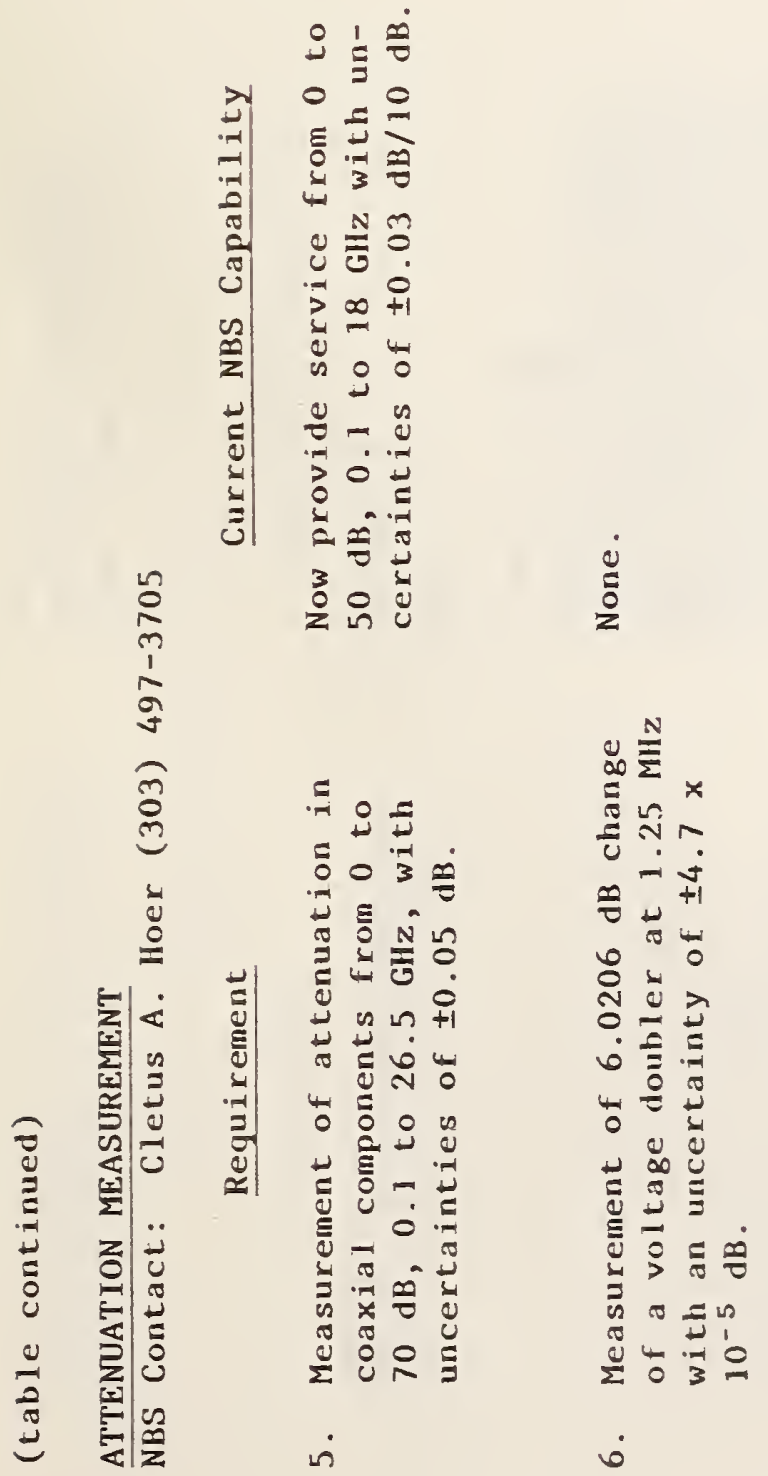

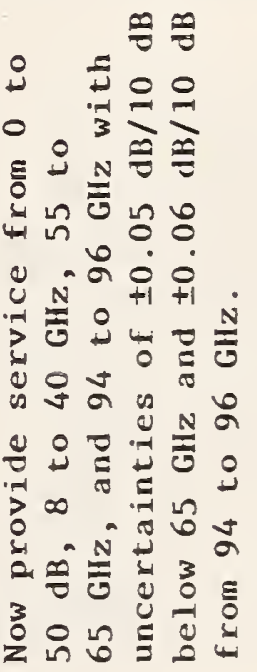

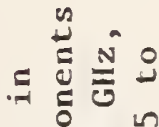

ㅎํㅇㅇㅇㅇ

苟

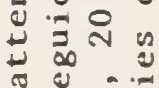

๙

+4 용

ํํำ

政

造。

的㫕

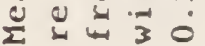



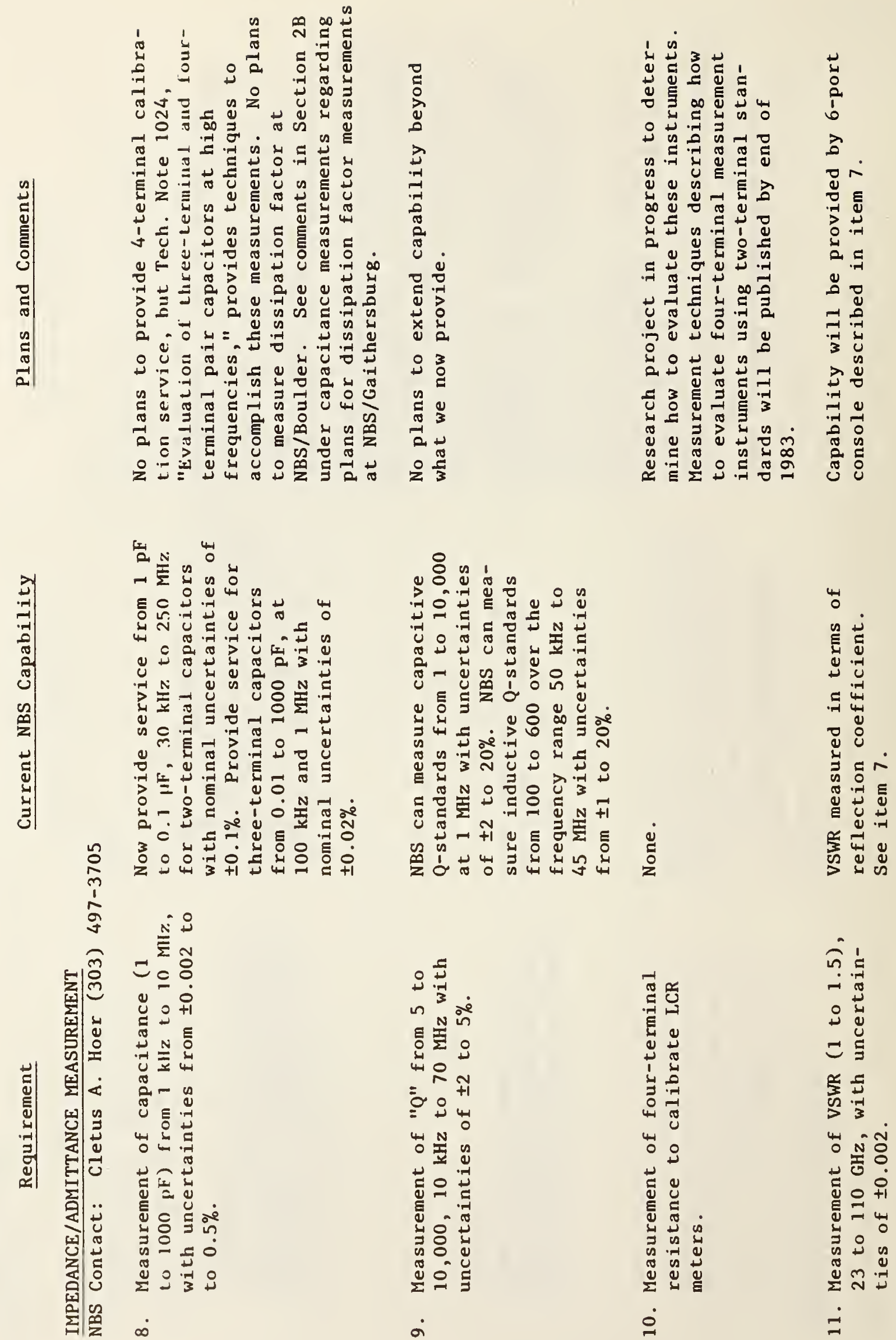


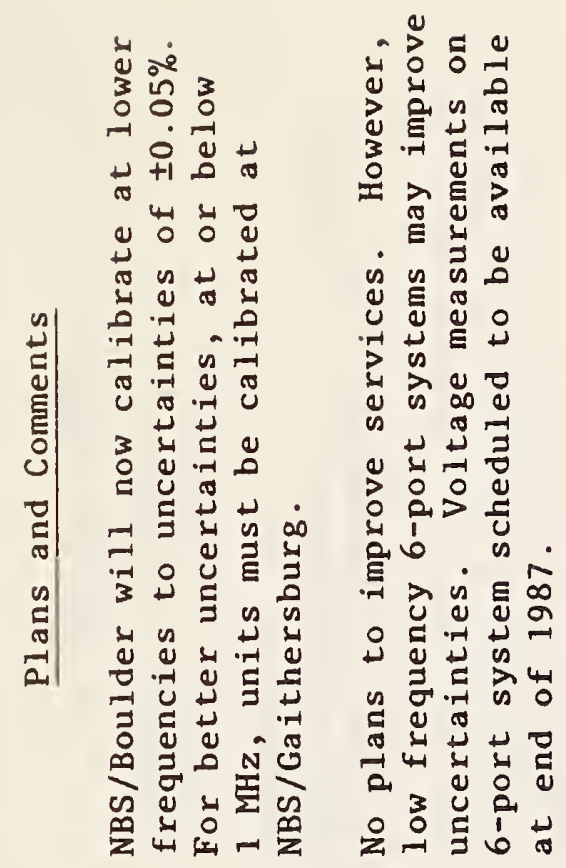

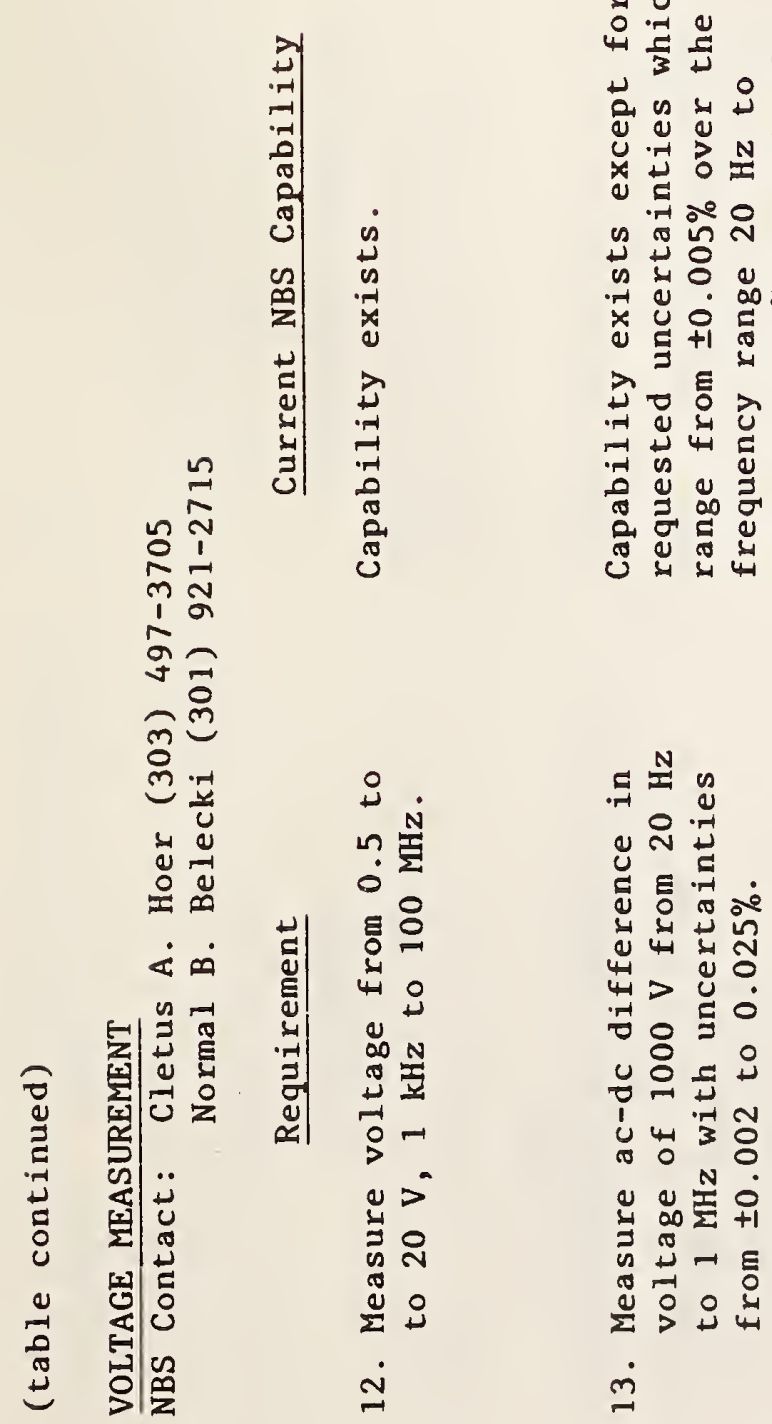
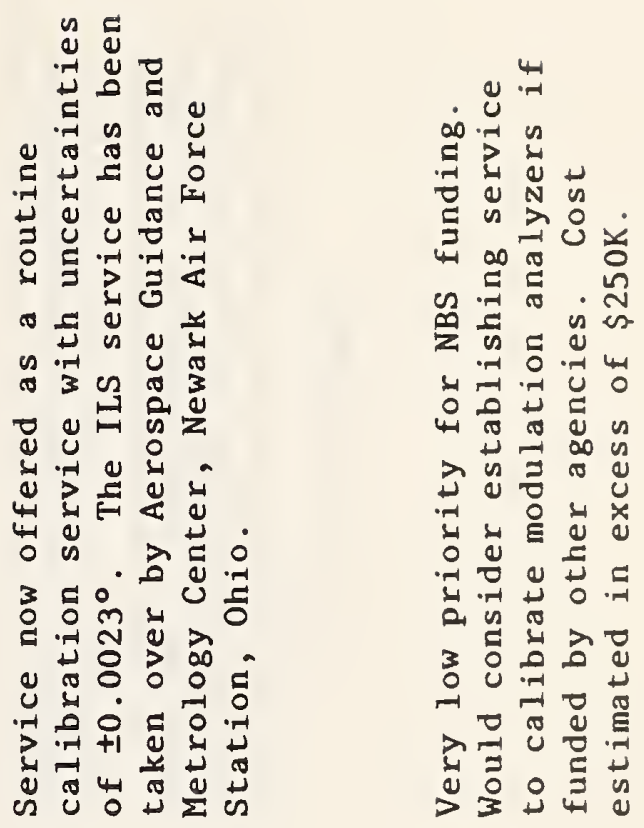
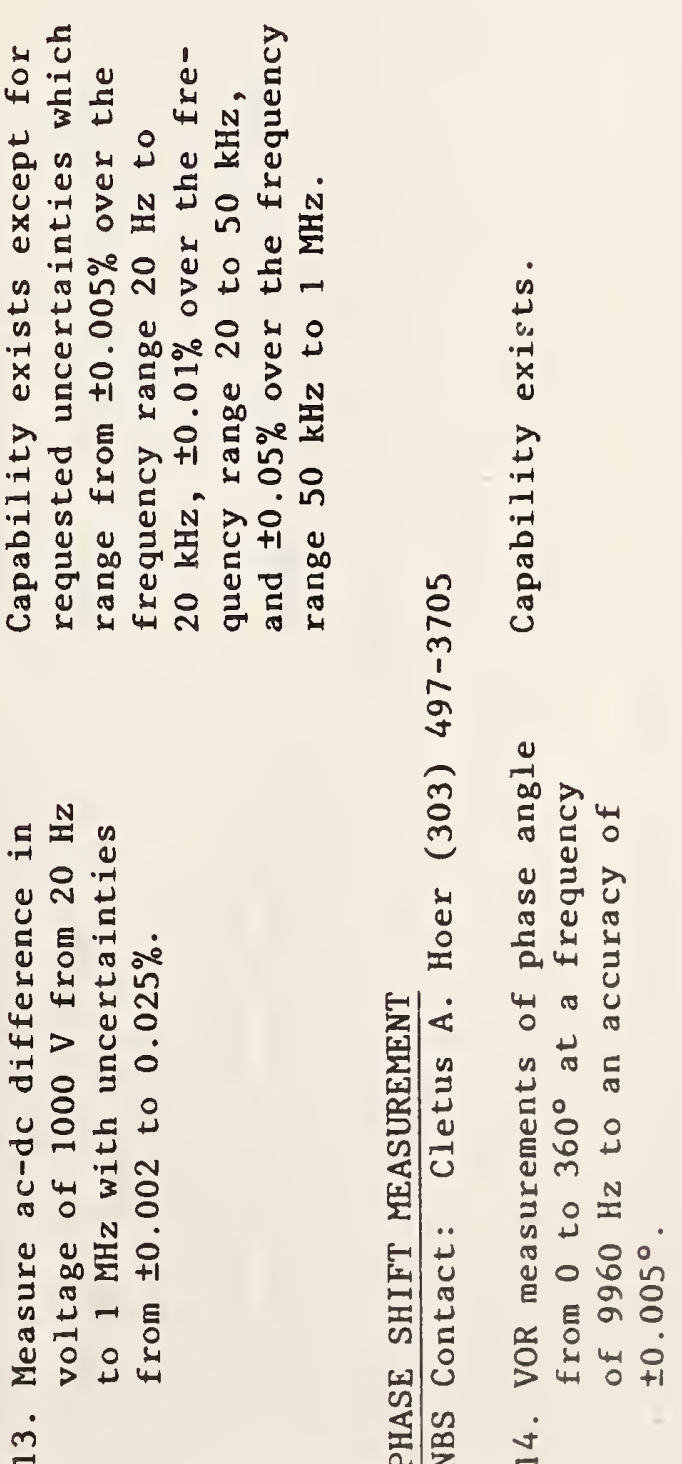
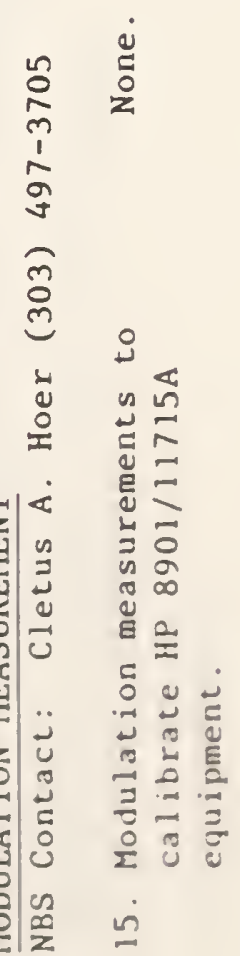

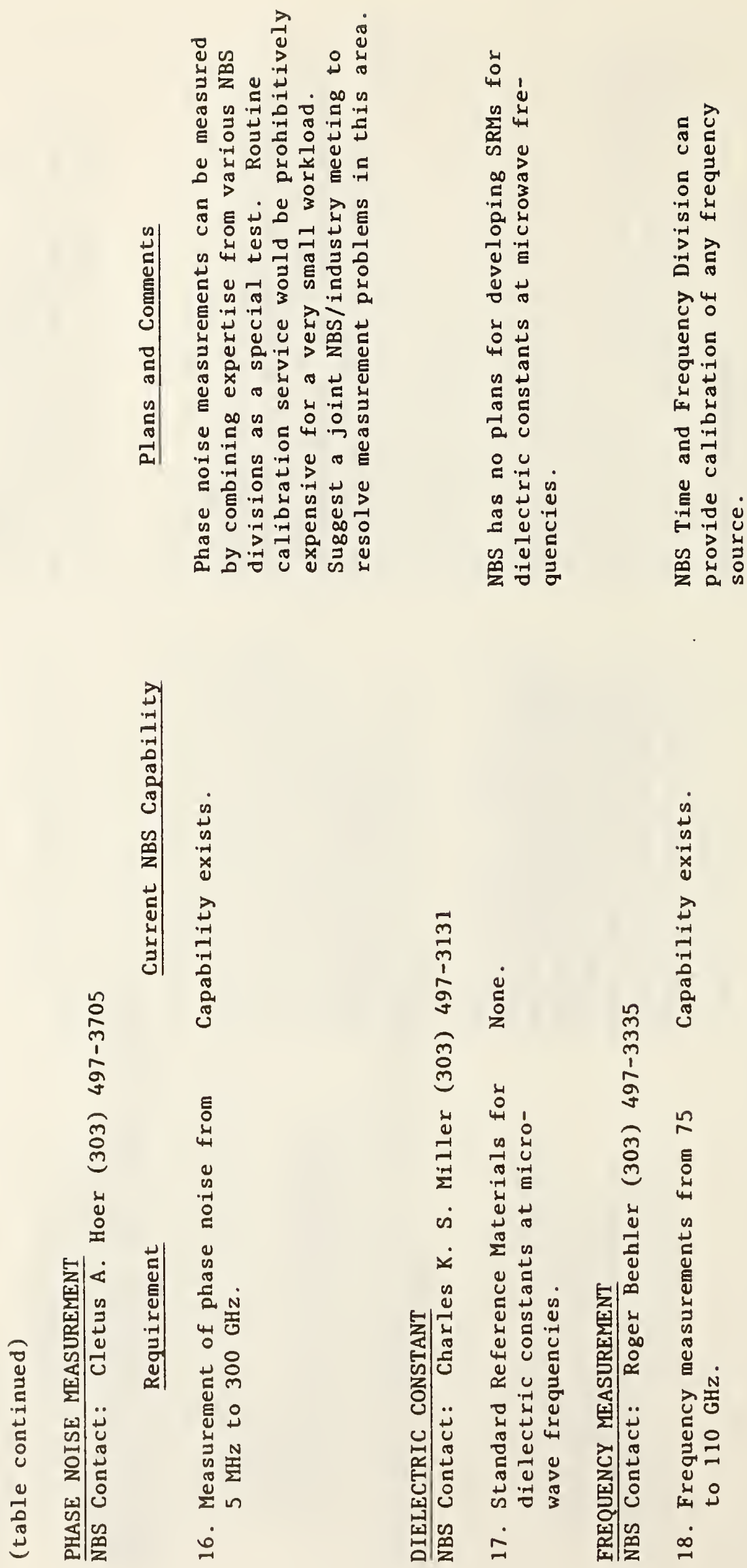
in

E E

ช)

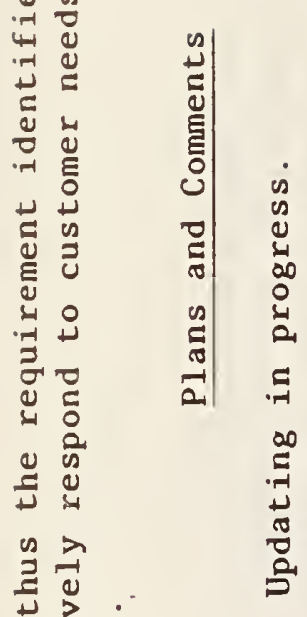

$\approx+\frac{1}{4}$

당 \&

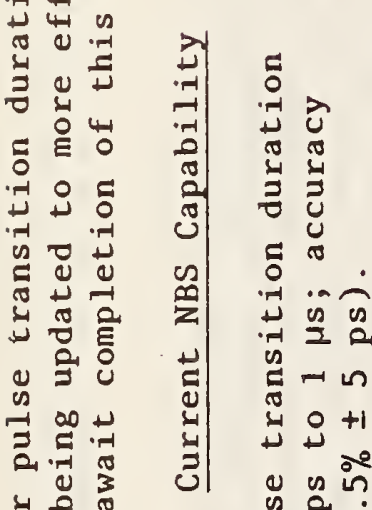

ก)

满 is 0

n 1

E⿱⺌兀)

我|

$>\sqrt{5}$

is a

ט1

$\stackrel{2}{3} 0_{+1}^{0}$

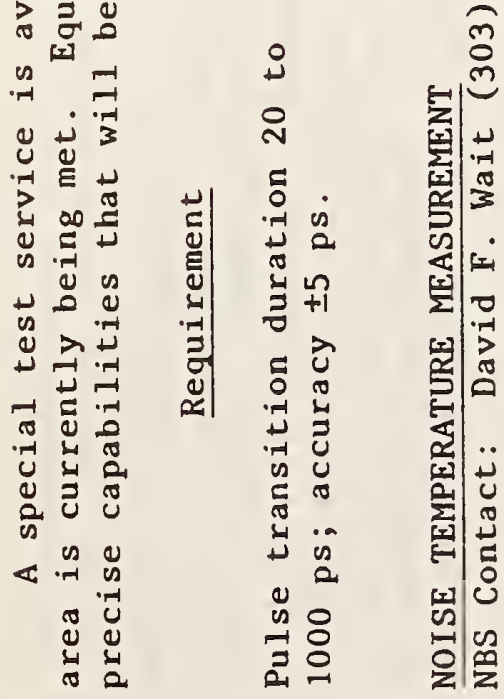

भ

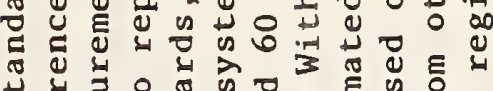
话

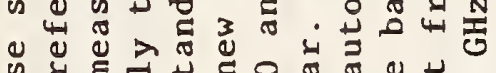
भ घ E 일 उ $\pi$
$\pi$ 퓨

3 क ○ 0 过 U है त

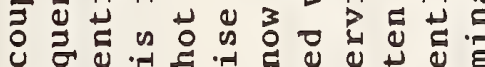
Q

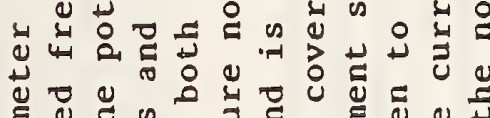

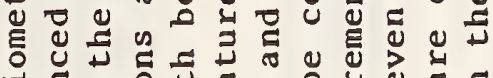

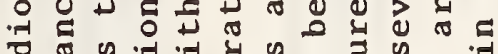

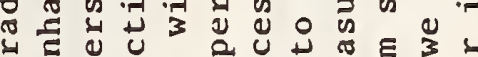
4 ब एँ ० ใิ त

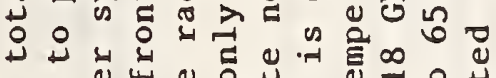

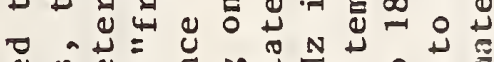

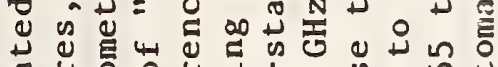

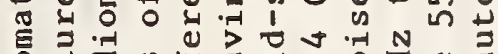

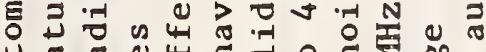
+ ส

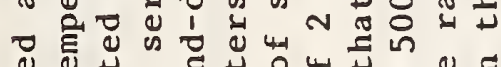

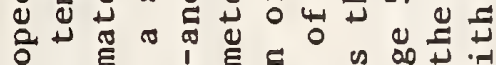

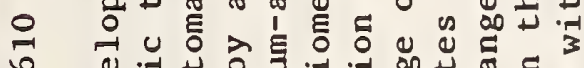

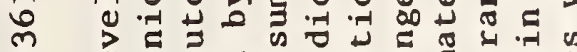
12000

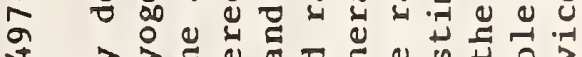
तो

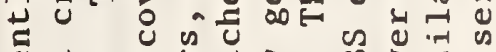
बै 0 in 3

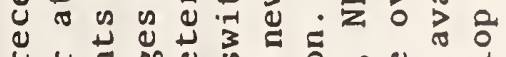
4 यू

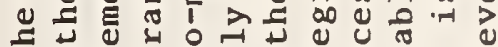
प्र 일

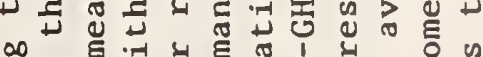

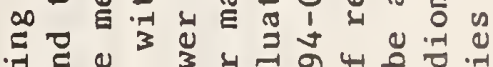
न ㄴ

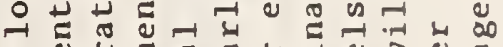

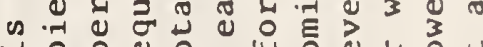
- ही है닌 थ

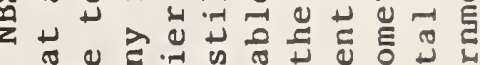

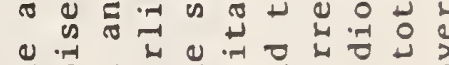

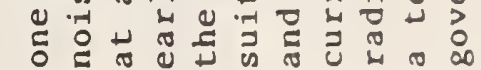

-

บ

$x$ औ त

ง

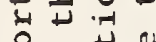

낸ㄷㄴ

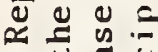

บ

造.

(1)

피용

- $\int^{4} \cdot 4=$

- $\rightarrow$ 元

$\nabla>$ \&

许皆 0

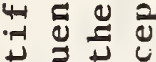

岂

$\div$ (4)

- $\begin{array}{ll}1 \\ -1\end{array}$

농

的的

ㅇํㅇ 이요

赵

잉

-

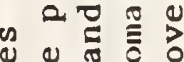

-

윰

วิ

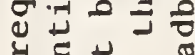

4

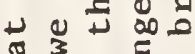

- 3 थ

क त

艺

Ш

들

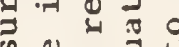

ช ن ข

U.

(1) क क

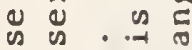

-

อ ช.

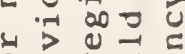

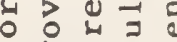

อ u

य 0 出

$\stackrel{E}{\Perp} \backsim \dot{u} \omega$

도에

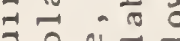

대

ป

एक वे

ป ᄂ

E 늘 है 

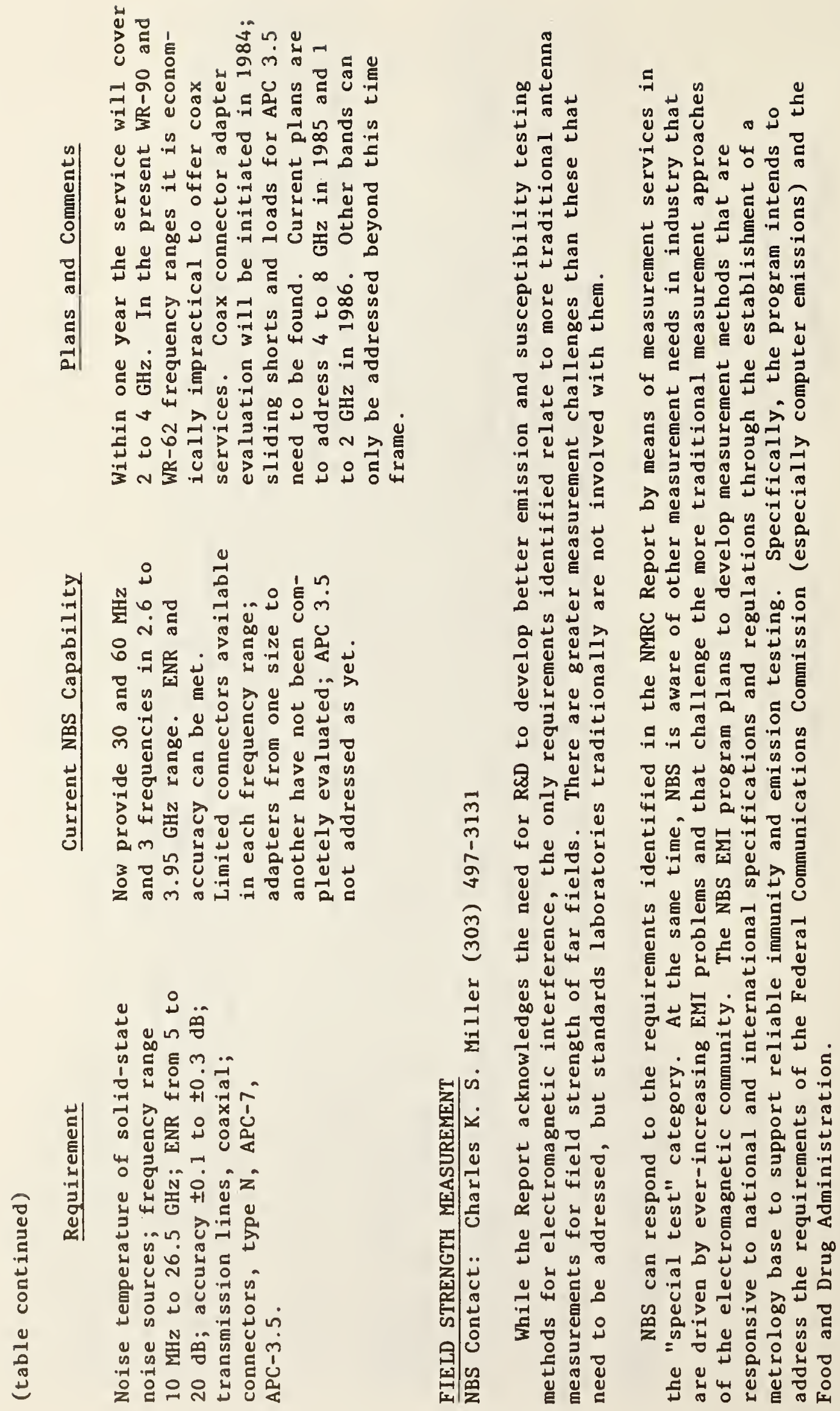


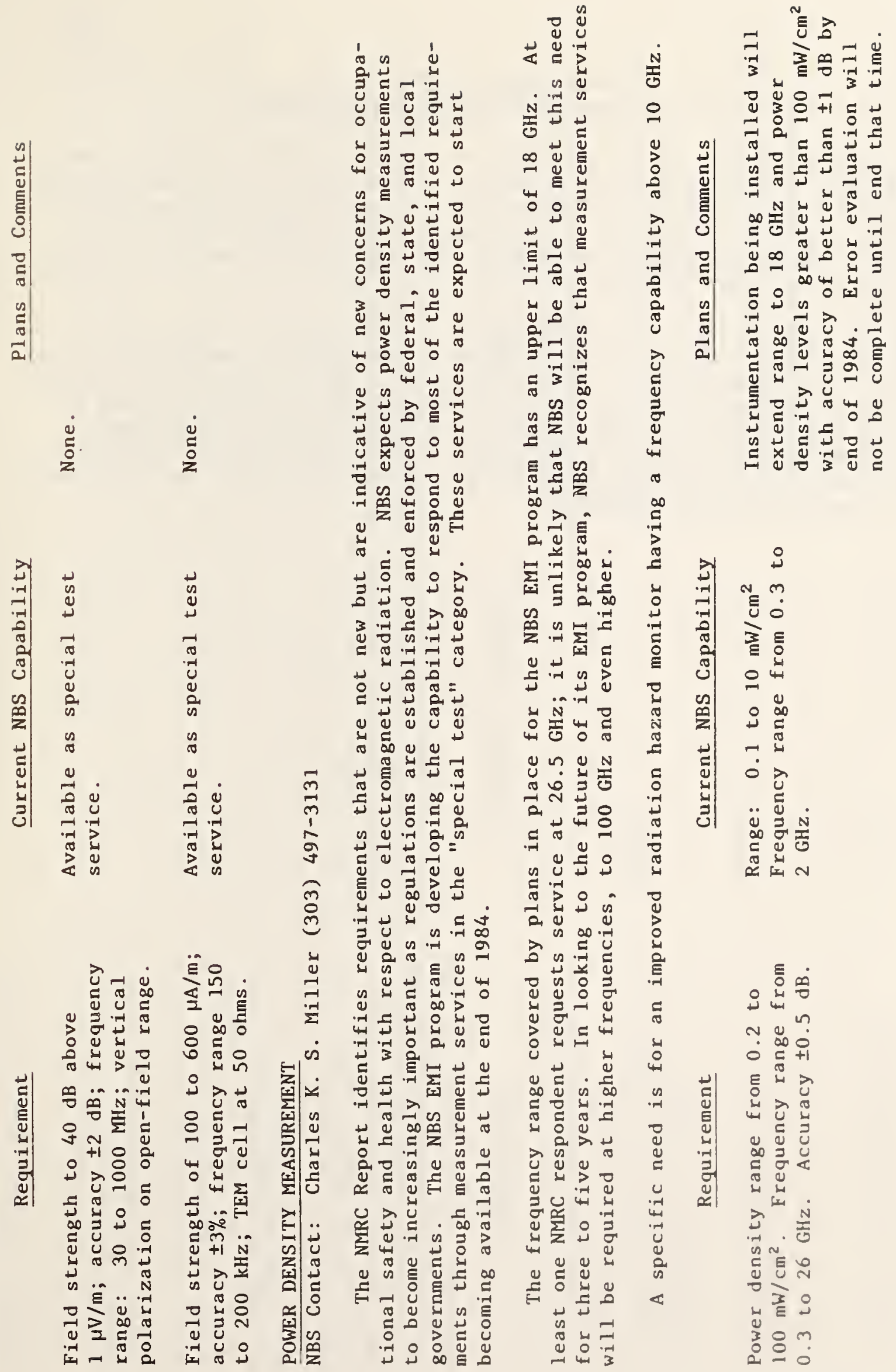




\section{RESPONSE TO SECTION 2D \\ ELECTRO-OPTICS MEASUREMENT REQUIREMENTS}

The usefulness of the study is somewhat compromised by the small number of responses to the electro-optics portion of the survey. Dr. Richard Miller, Chairman of the Electro-Optics Subcommittee has indicated his plans for a program to reach the electro-optics community and provide additional input. When these additional data are available, the report should be very valuable to future planning for optical electronic metrology.

NBS recognizes that many of the needs in this technical area are classified or proprietary. In addition to the information presented in this NCSL Report, NBS does receive through other channels information that is used in establishing priorities. An important segment of the electro-optics community is represented by the Council on Optical Radiation Measurements (CORM). NBS works very closely with CORM, and CORM periodically publishes survey reports on measurement requirements. In Section 2D of the NCSL Report, the most recent CORM is summarized. 
苞

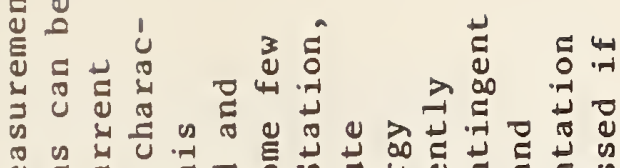

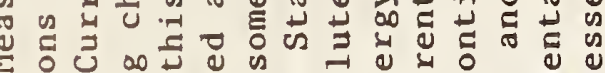
更

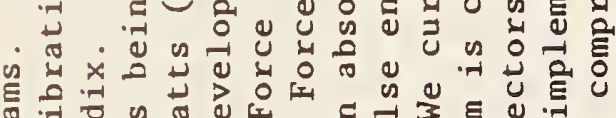
先

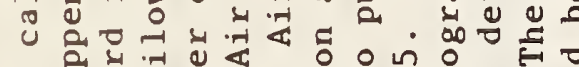
U $\Rightarrow$ द

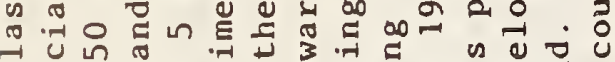
U ข 4 的

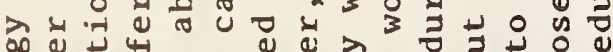

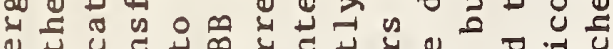
U

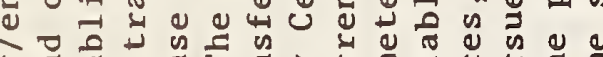

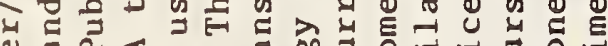
U 3 in -1 . थ

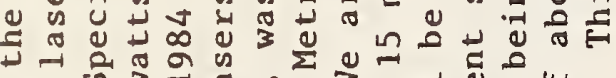
क क ज 3 की

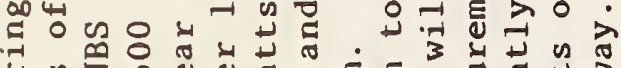

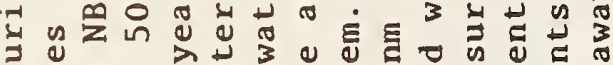

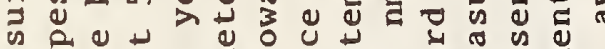

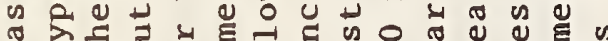
U 당ㄷㅁ

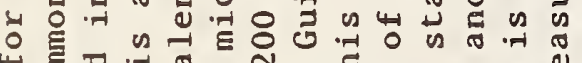
施

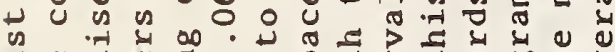

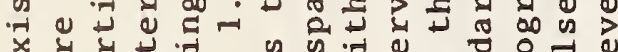
U

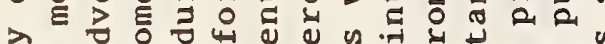
를 त

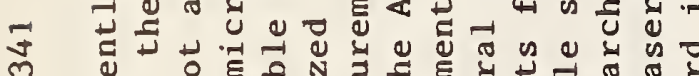
ก

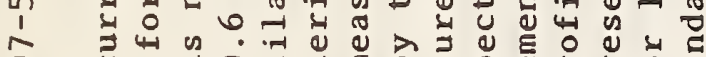
Iิ Uे

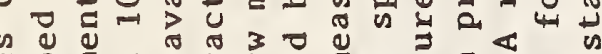

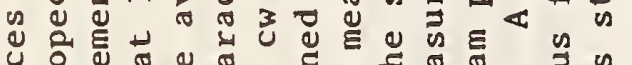

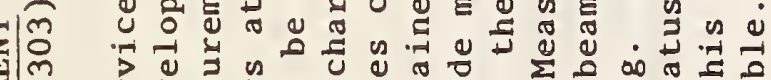

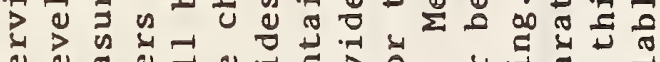

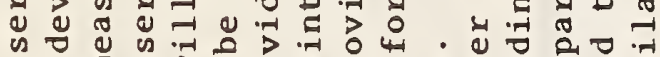

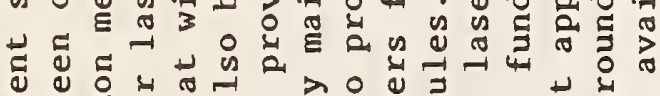

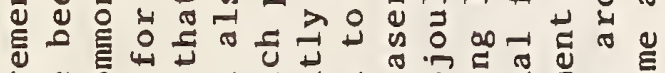

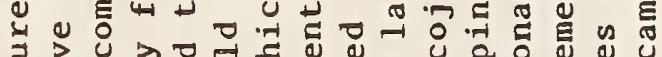

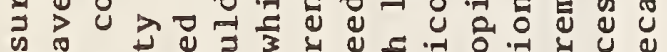

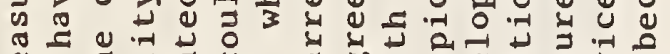

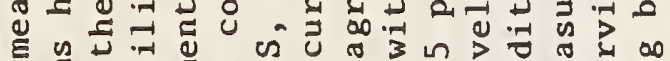
ह 4

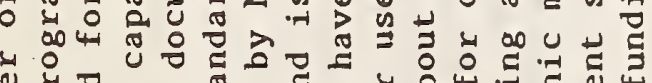
U है

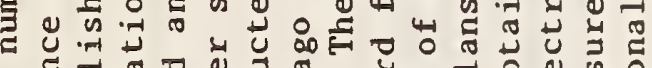
๔ त

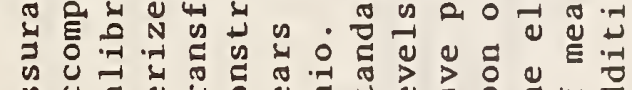

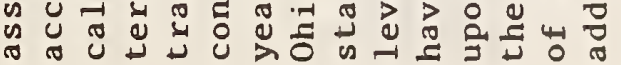
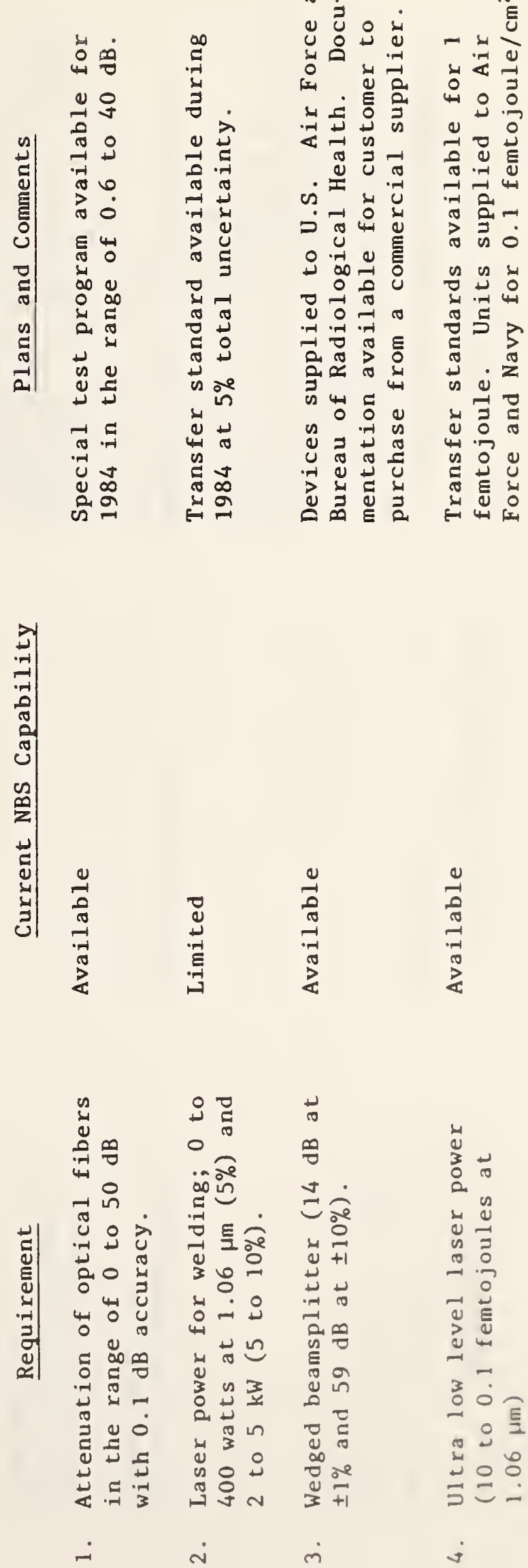


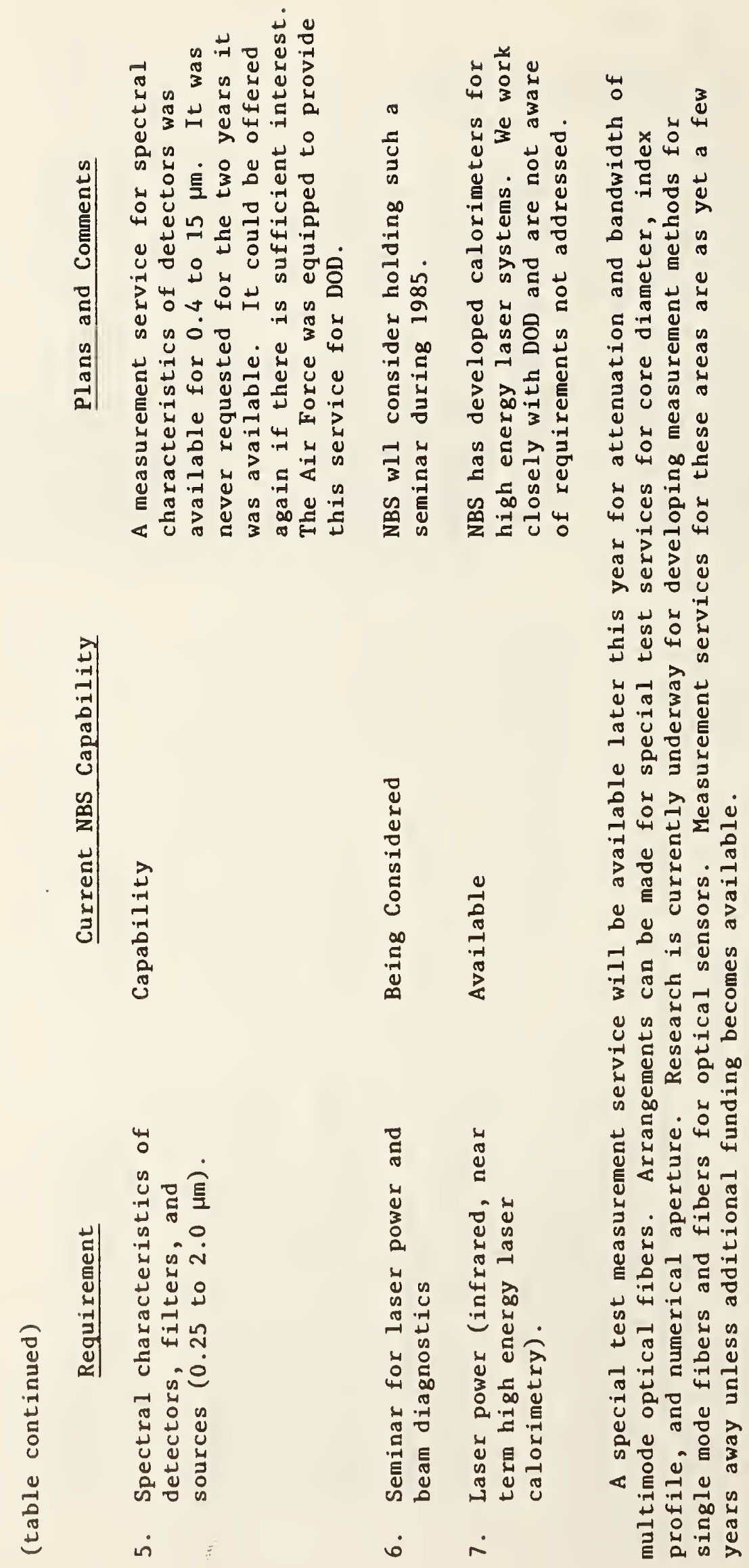


This section of the NCSL Report was structured to compliment and supplement the work of other groups addressing measurement needs in radiometry. of particular note is the prior work of the Council on Optical Radiation Measurements (CORM). In preparing the NCSL Report, however, particular emphasis has been given to the needs of the aerospace community. This segment of the electro-optics community has not been completely represented in CORM. The NCSL Report thus forms a valuable addition to the information base utilized in planning future NBS activities in this area.

The measurement needs identified by the respondents to the NCSL survey and the NBS comments are presented in summary form in the following table. Because of the small number of responses to the NCSL survey, only part of the NBS program in radiometry and spectrophotometry is presented here. 

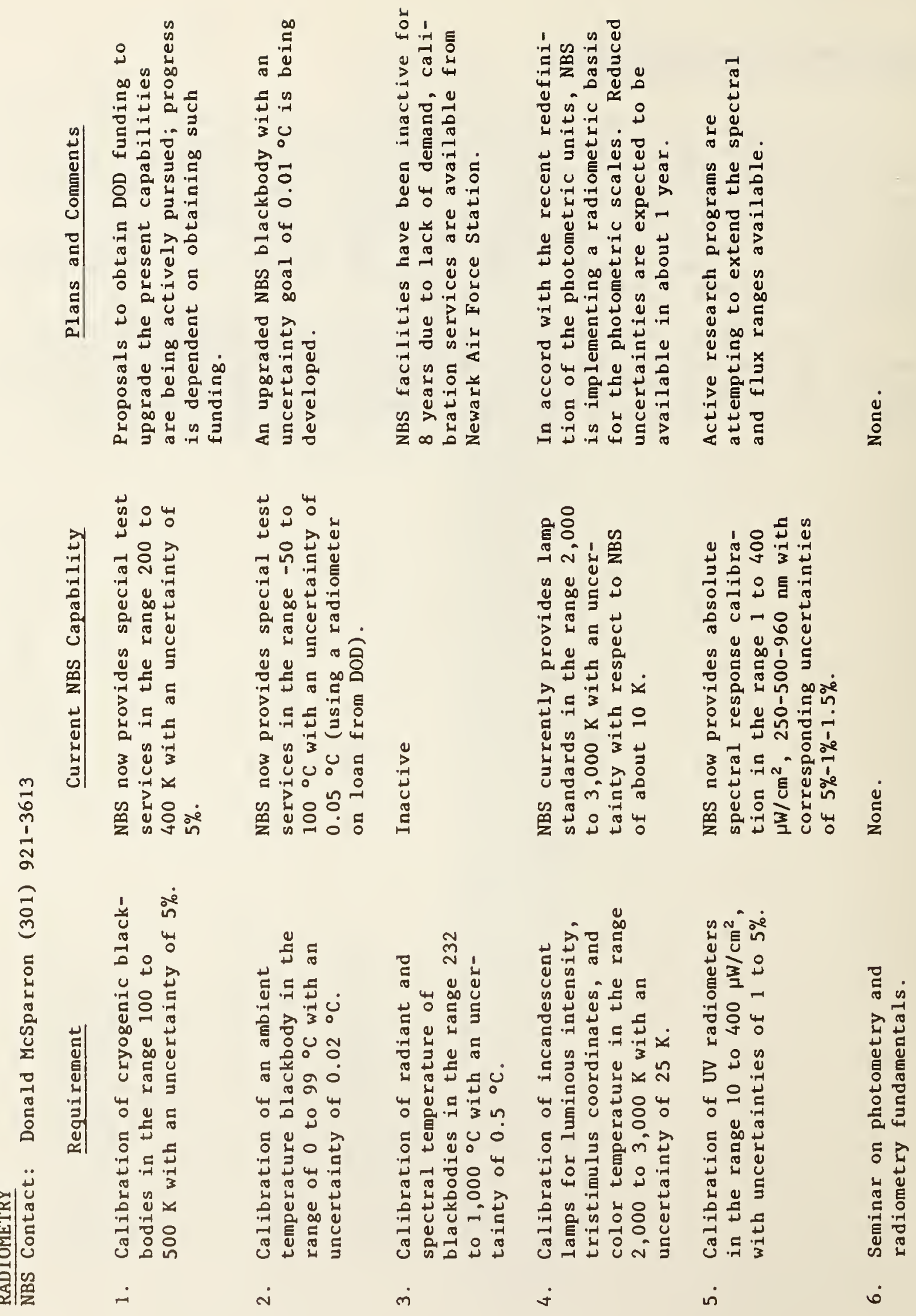

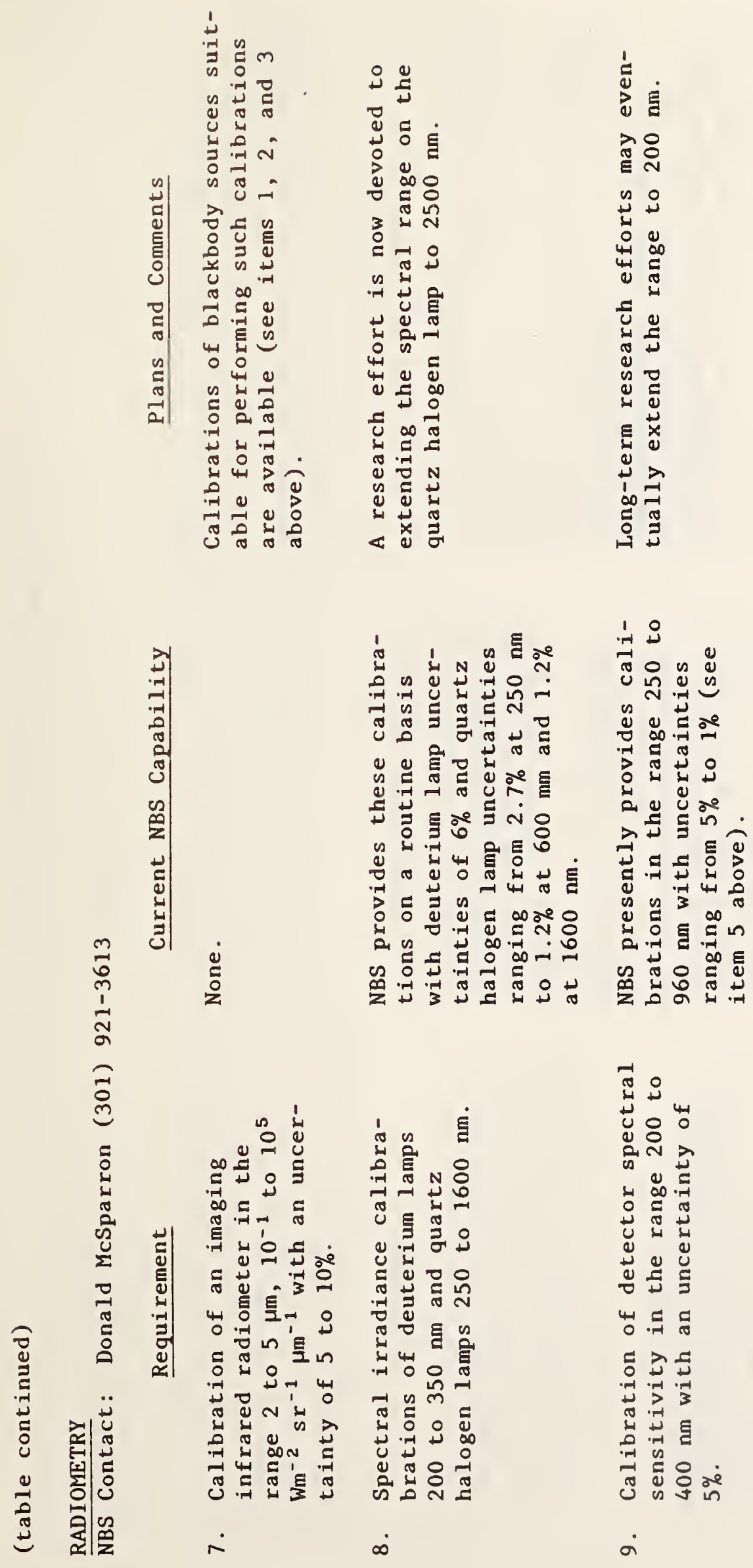

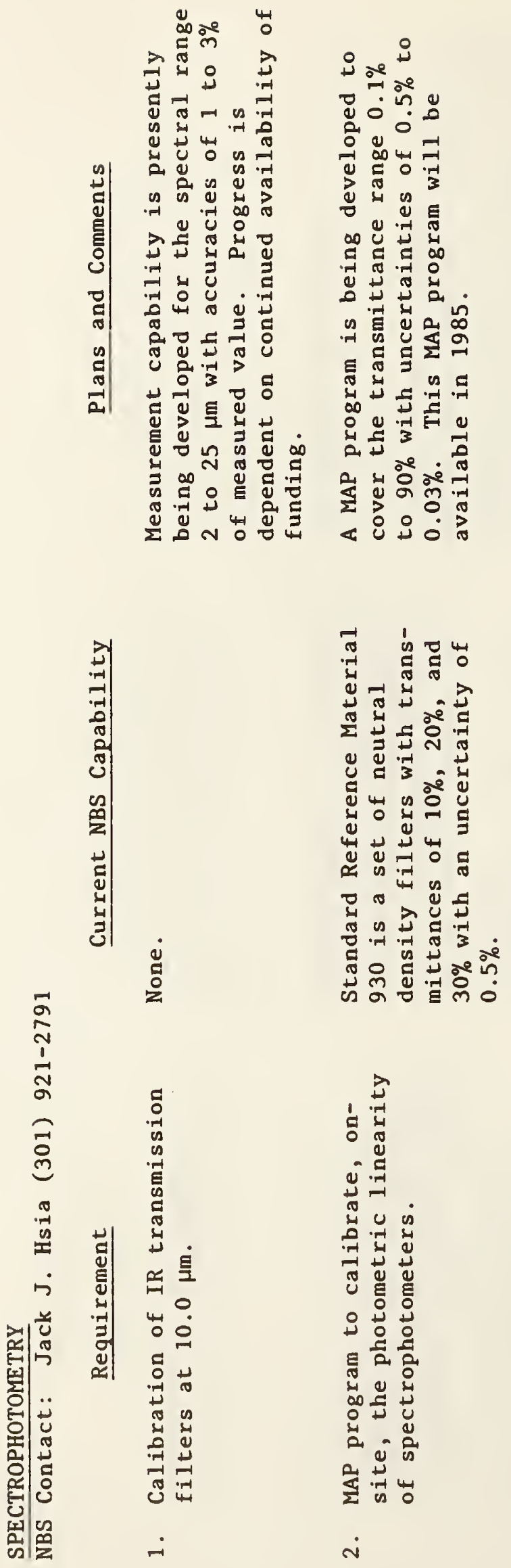


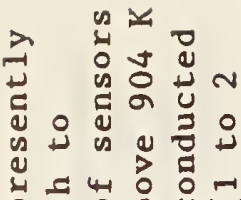

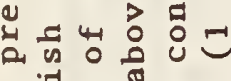

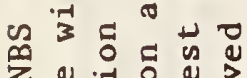

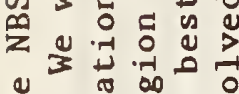

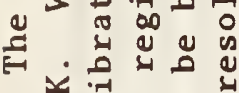

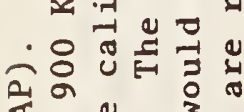

$\leftleftarrows 0$ \& 3

$+\infty$ ᄂ

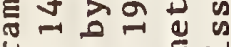

$\infty$ ह 등 응

0 언

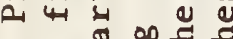

4 थ ग

U

ส

난 U

u 4 을 를

as

๘

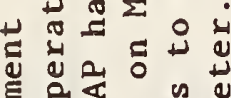

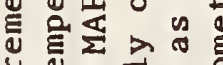

zo

넝 $\infty$ o 을

भ 1 过

บี

(4) 동

돈

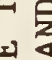

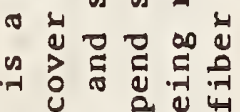

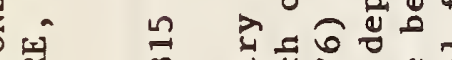

西,

约

虍

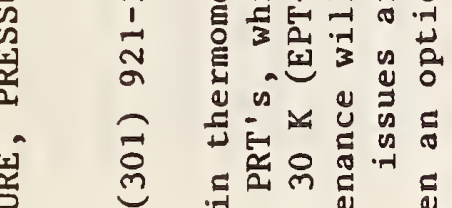

.

눌

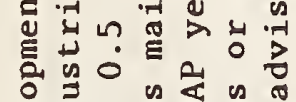

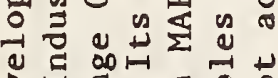

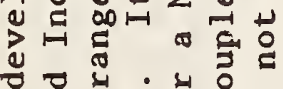
- 0 is 0

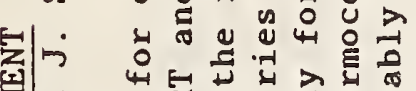

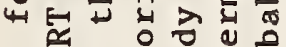

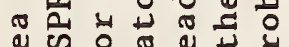

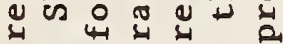
त)

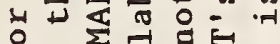

초

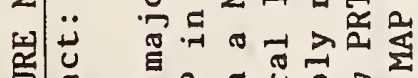

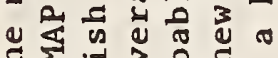

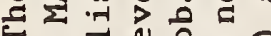

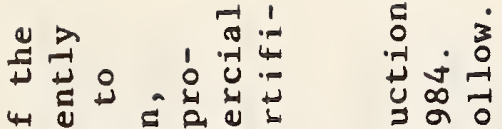

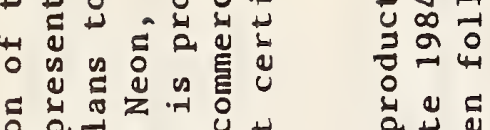

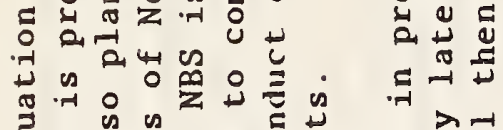

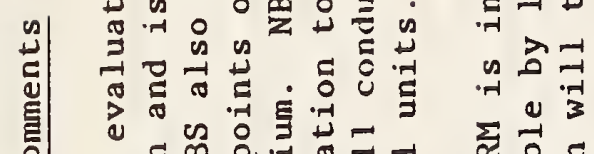

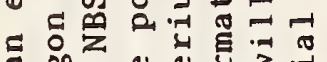

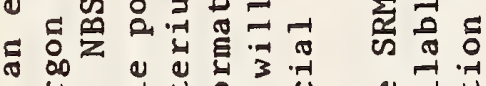

จ वृष्ष

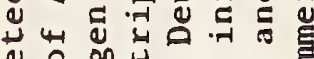

त्रे

हुำ

ถ己

ช

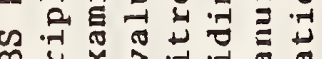

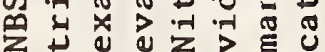

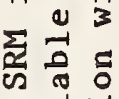

ब

गु

돌 봉

골

u

ฝ 굴

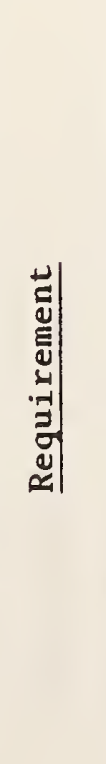

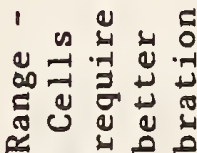

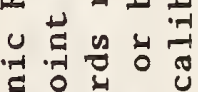

远公

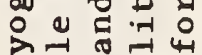

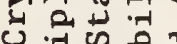

U न्य

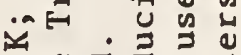

ल $\Rightarrow$ वृ वे व

กิำ

N न

$\checkmark$ 宁牙

$F$ 안

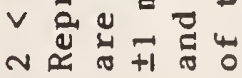

苞范

कิ

कำ.

a담

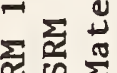

密焉要

톨

]$_{7 \rightarrow}^{-7 \pi}$

年.

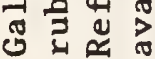

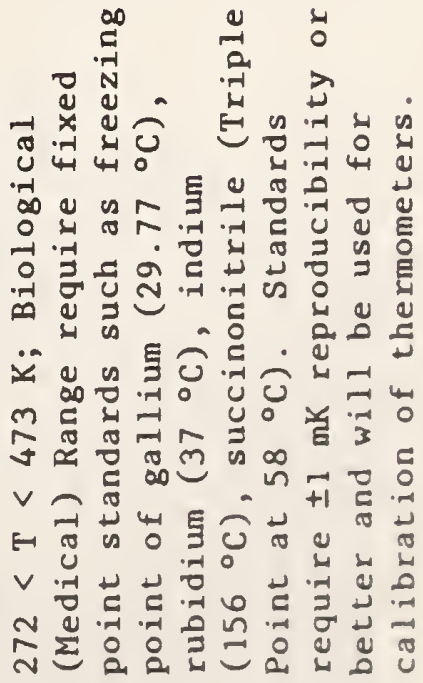

v 

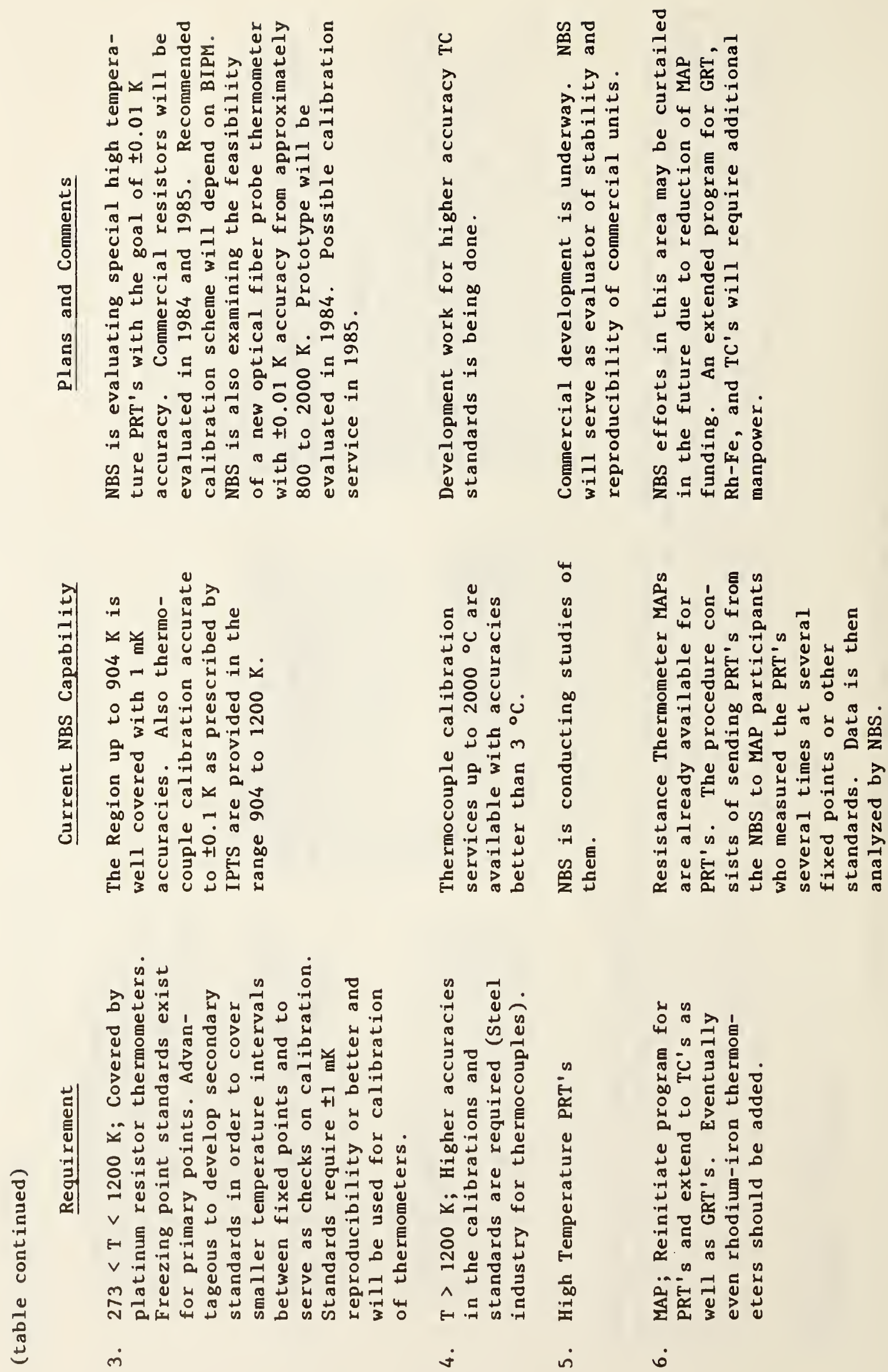

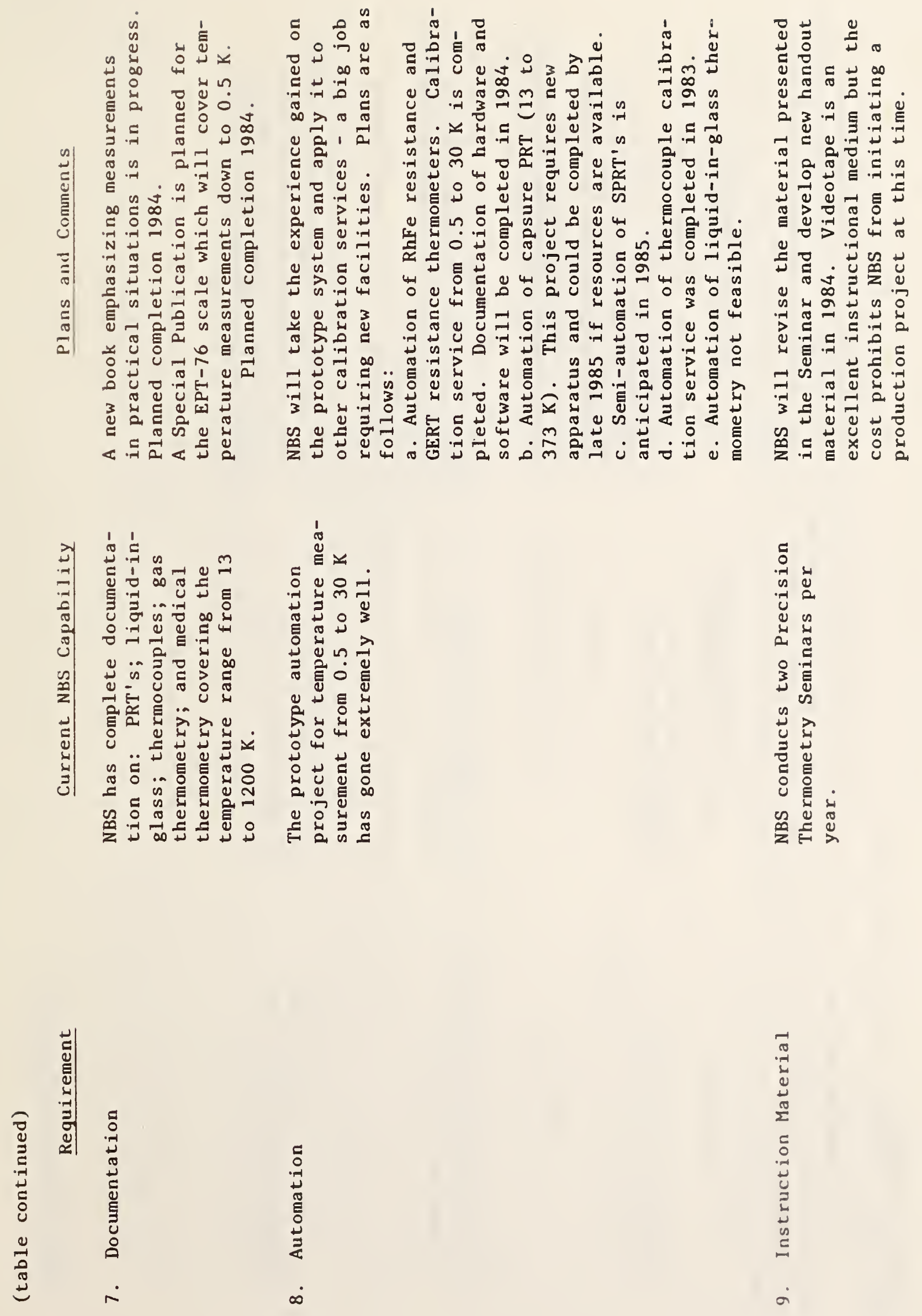


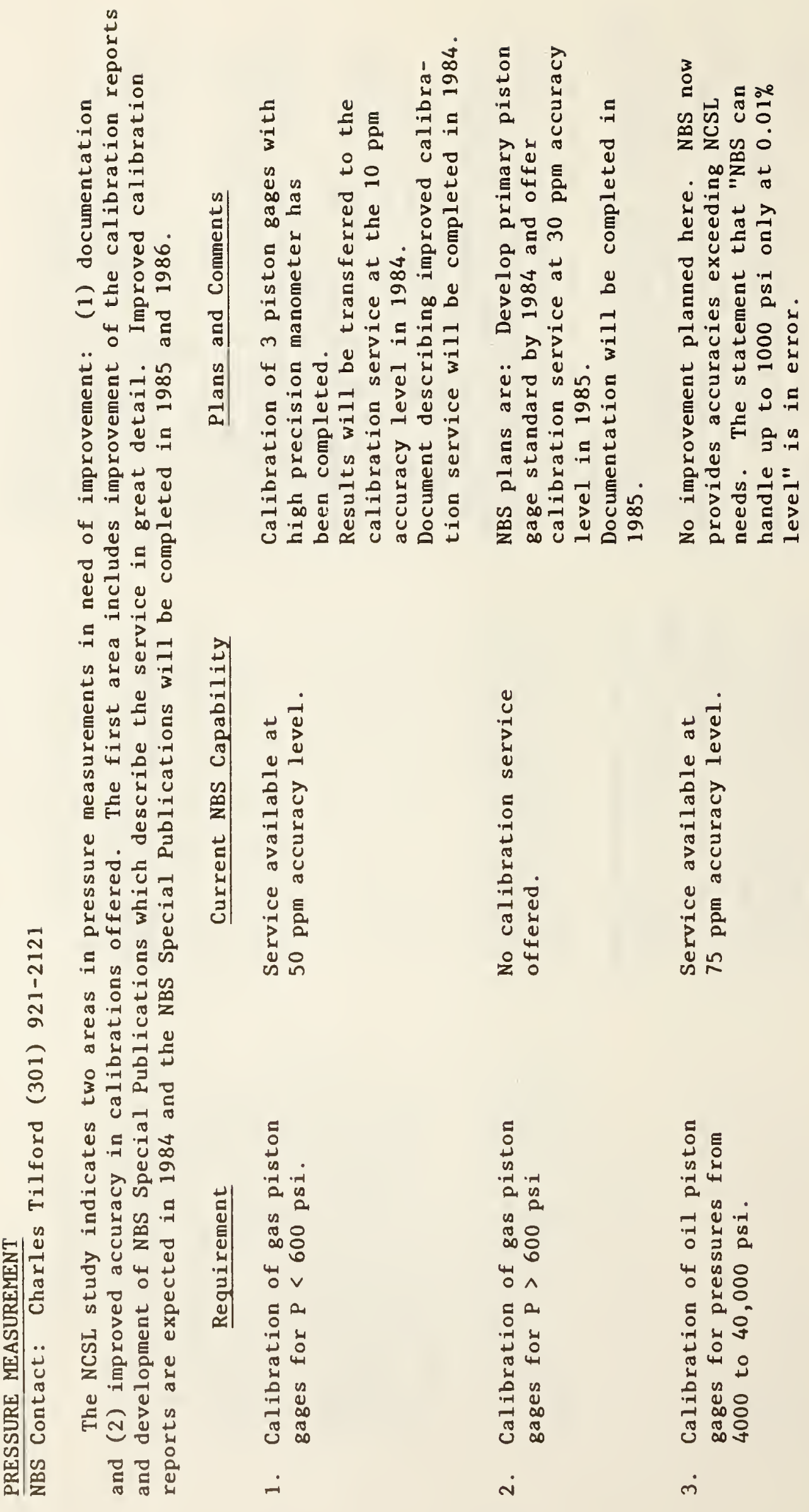




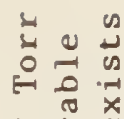

0 .

월

$\therefore$ 要

秀证

(1) is $\frac{m}{z}$

$\infty$

내응

$\rightarrow 00$

$\int_{0}^{E} \overbrace{}^{n} \frac{n}{2}$

31

य 1000

u

है 3 a v

(1)

J

ก 0 บ

च1 0 - 10

(1)

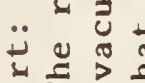

E $>\frac{1}{4}$

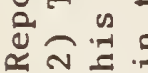

先 is

$z$ is $>$

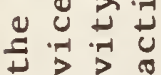

$+>>$

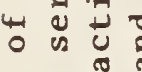

V $\quad \infty$

N

I

N

a $\quad 0$ o 0 U

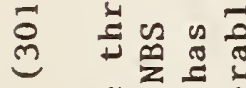

牙

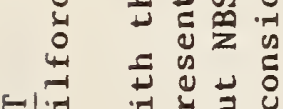

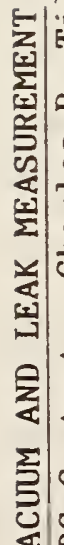

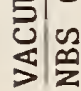

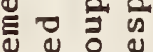

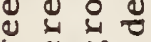

$\infty \infty_{\infty}^{\infty} \infty$

$\infty$ ठ

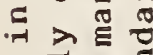

o $\vec{\sigma} 山$

क व

is
음

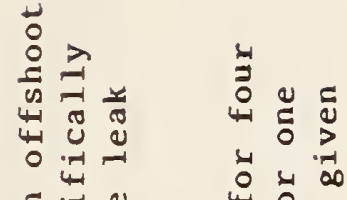

ริ

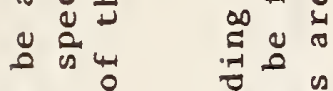

च.

उत्र

ข

ॠ

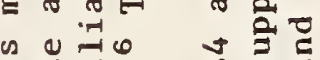

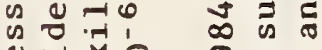

ข. $x \circ$ o

फू

范交

我

$\underset{I}{\infty}$ is

ป

는

i

$\pi=$

$\infty \frac{\pi}{\pi}$

is is

ธ

$\rightarrow-1$

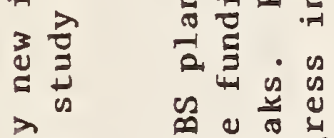

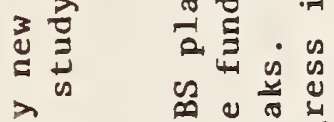

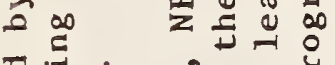

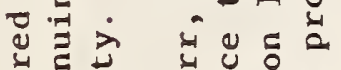

品

ठํำ

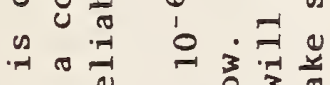

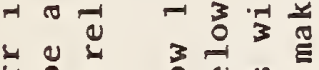

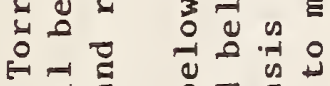

1

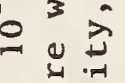

टू की

व

त्र

3 बृ

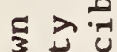

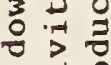

5 표은

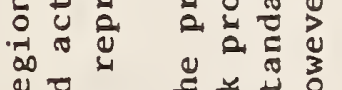

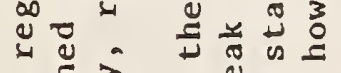

ข

है

a.

ए

कै का is

แั

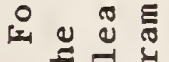

ป⿻
过

of \& 3

y

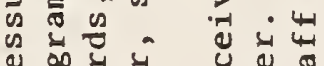

$\sum_{i=1}^{\infty} \sum_{i s}^{\infty}$

$\infty$ i

ฮ

بั

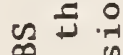

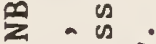

氙

00

2.

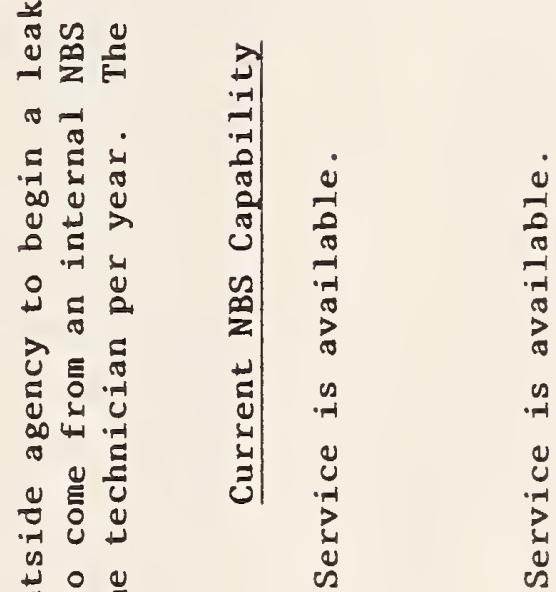

¿

की

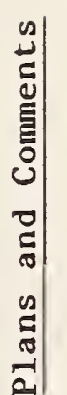

की Uั口

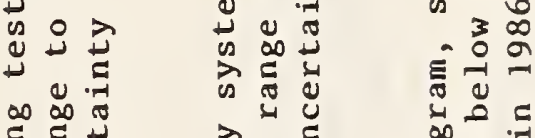

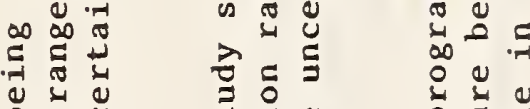

\&

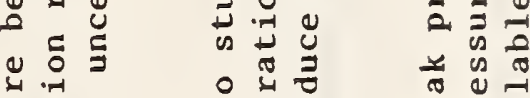

ब

कृ

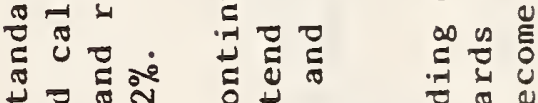

虫

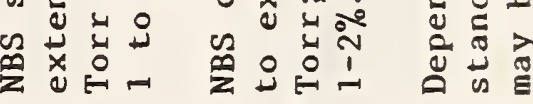




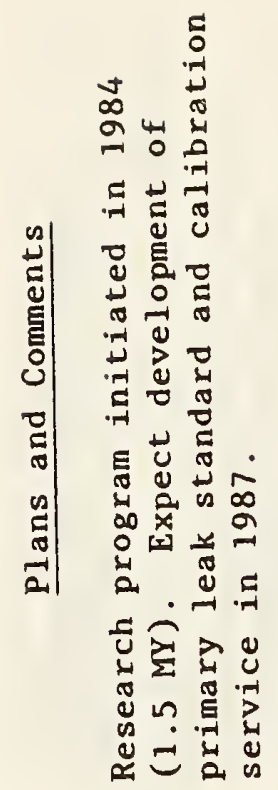

|च.

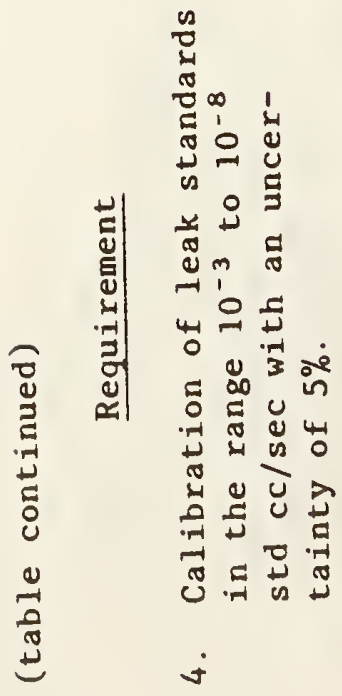




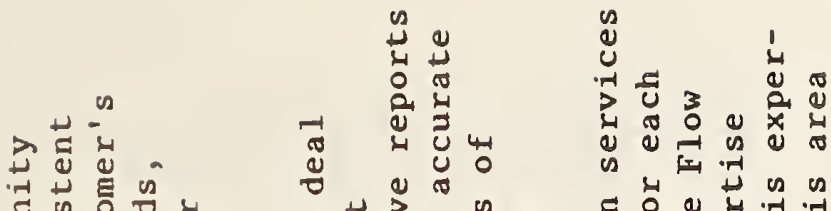

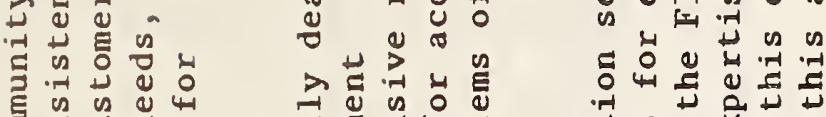

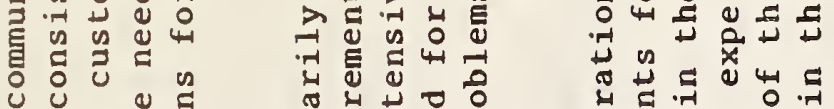

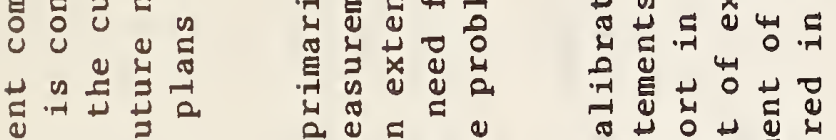
눈 उ.

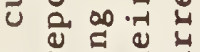
巳 से कू वे Бี : $\rightarrow$. U. प

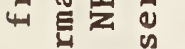
ت

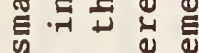

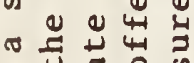
मा० 고율ㄹ (1)

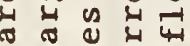

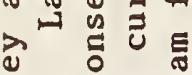
$>0$ 월

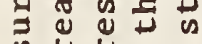

$\vec{\infty}$ 告

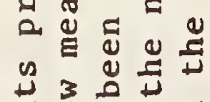

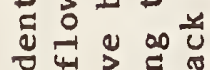

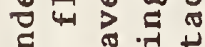
ป

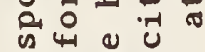
近 0 व

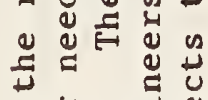
चั ๙ \& ब

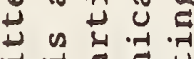
न $\rightarrow$ ह 둔 U क मे

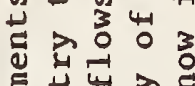
论 苟司 'न 들

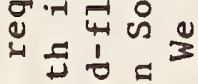
过

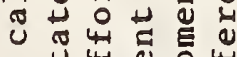

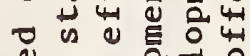

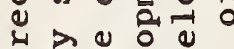

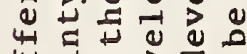
出.

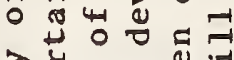

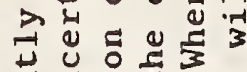
进步 过

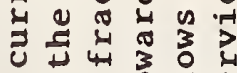

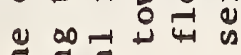

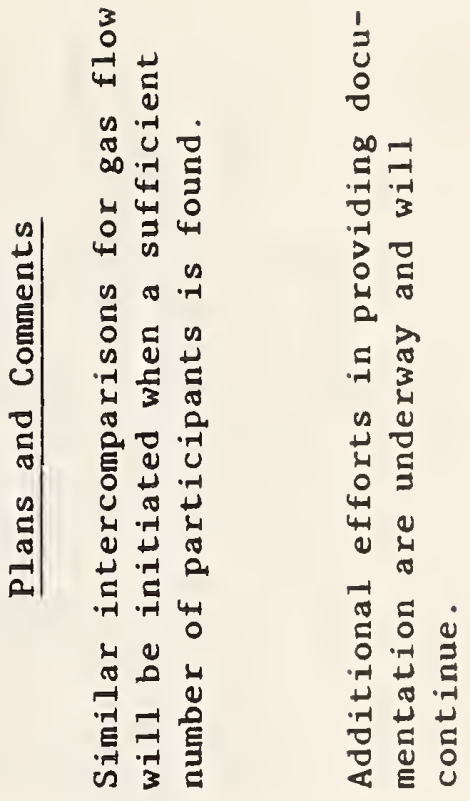
स ฮ न II $\infty \omega^{\infty}$

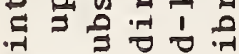

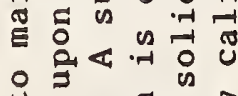
뭉 है

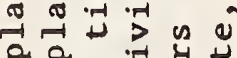
य व है. 开 的

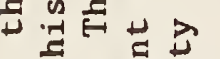

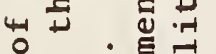
대 हᄃํำ

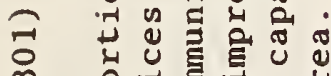
范 震

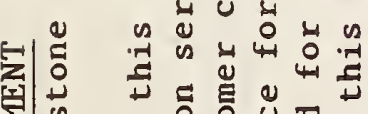
म म

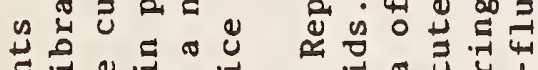

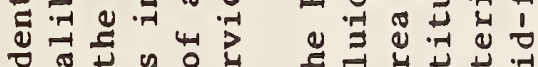

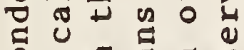
เั की 进出范范

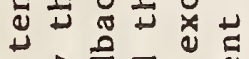

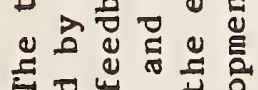

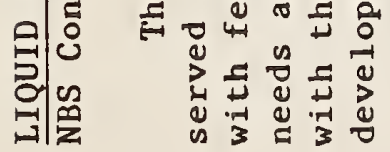

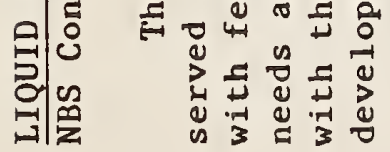
4 थ

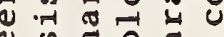

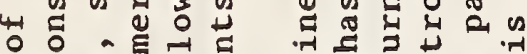
.

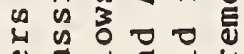

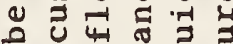
है

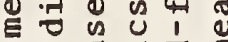

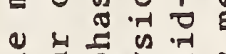
岂先 다 $\rightarrow$ का $\infty$ 造

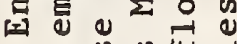

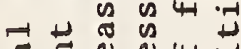
ठै

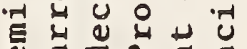

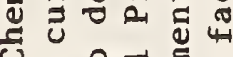

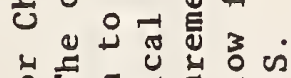

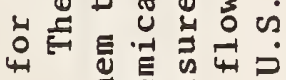
先

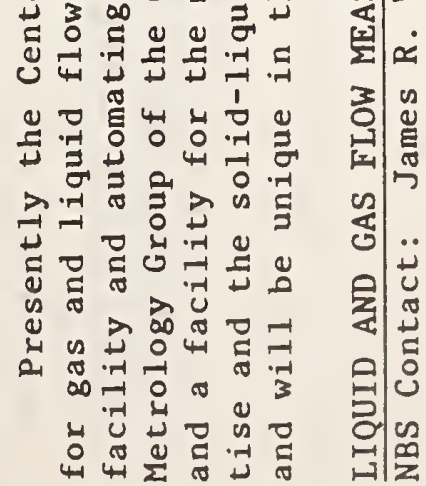

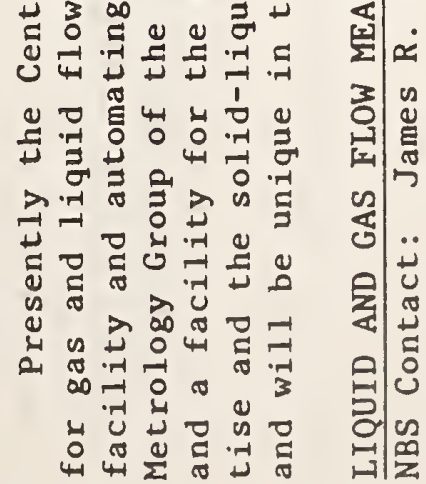

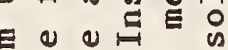
हี

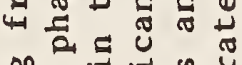
正。

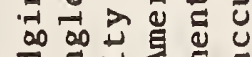

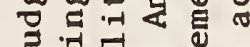

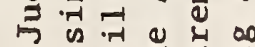
를 Ð

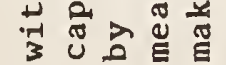

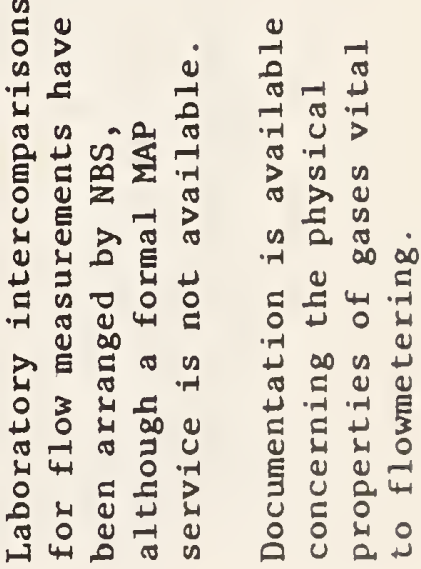

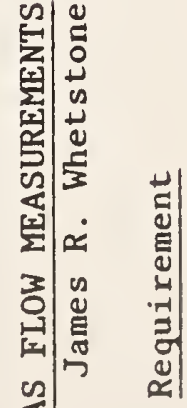

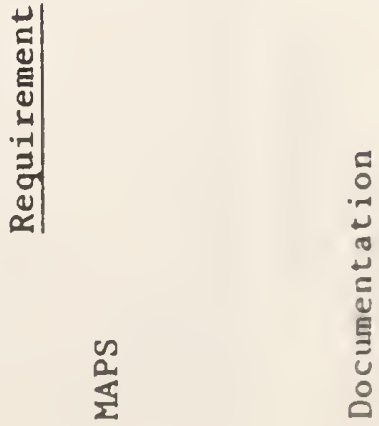




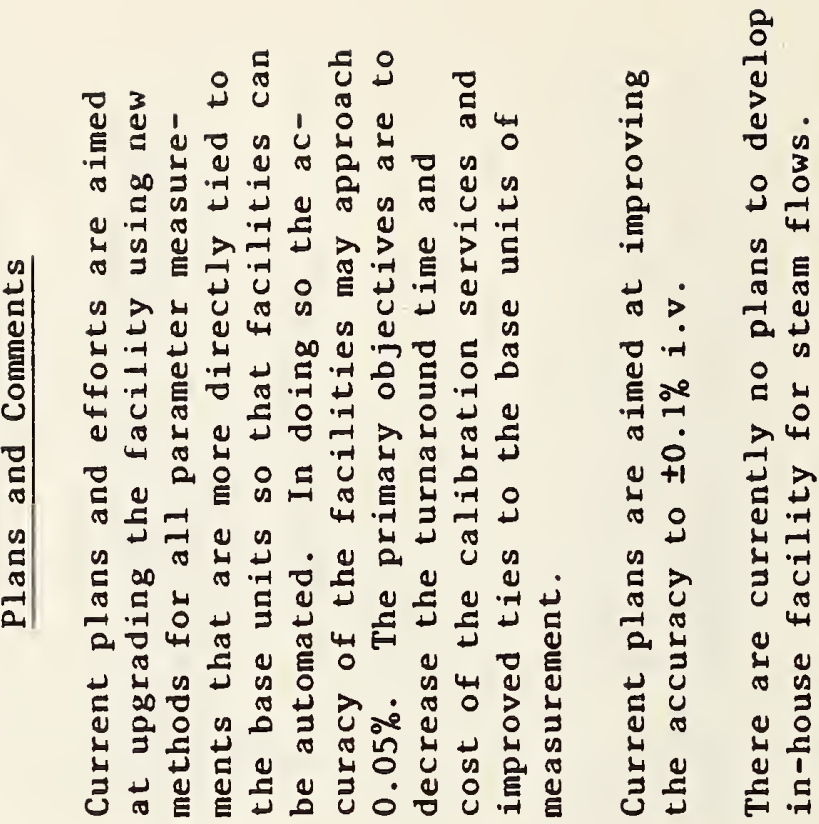
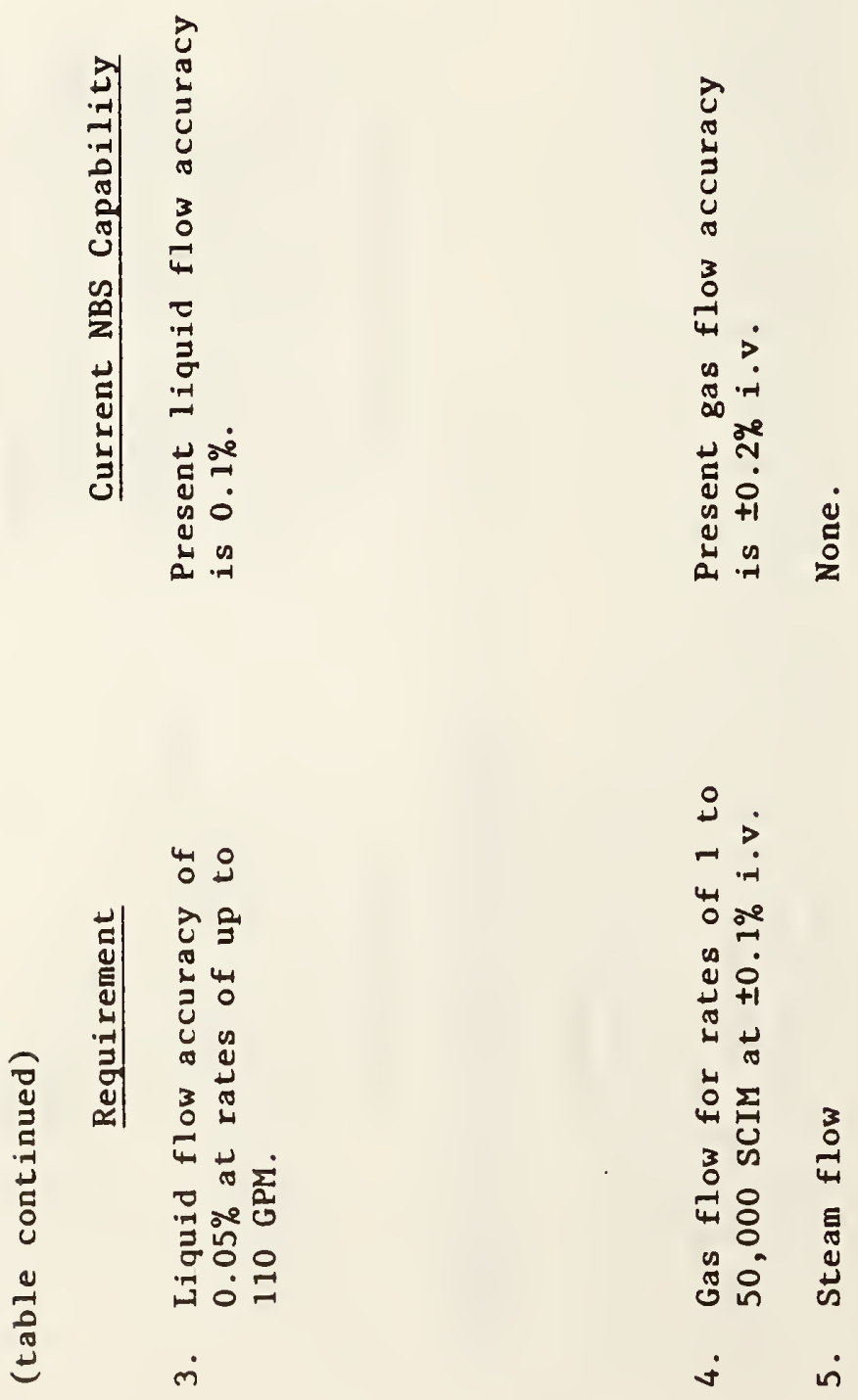
THERMAL CONDUCTIVITY/CONDUCTANCE STANDARDS

NBS Contact: Jerome G. Hust (303) 497-3733

The NCSL Report indicates the need for a much wider range of SRMs including both a wider range of temperatures and of thermal conductivities. Within the funds available, NBS is attacking the highest priority needs.

NBS' Center for Chemical Engineering (CCE) provides measurement services of interest to the chemical process industries. The small but continuing effort of CCE is directed towards satisfying needs of the kind identified by the NCSL Report. The most critical needs of industry at present are:

a) A low conductivity solid SRM with a range of conductivity comparable to geologic, plastic, composite, or agggregate materials.

b) A low conductivity insulation SRM for use above ambient temperatures.

The high cost of production may prohibit the preparation of the low conductivity solid but work has started on the insulation material. A glass-fiber board (SRM 1450) is available for use at ambient temperatures.

ELECTROLYTIC CONDUCTIVITY

NBS Contact: William F. Koch (301) 921-2883

We fully agree with the Report that electrolytic conductivity is an area in which there are real needs for high-accuracy standards and traceability to NBS over the full range of $10^{-6}$ to 1 siemens $/ \mathrm{cm}$. These measurements are important in the pharmaceutical and power industries as well as for oceanographic studies, environmental issues (acid rain, water quality, etc.), and fundamental studies in the theory of electrolytes. These measurements have implications in health related areas, such as the effect of electric fields on living cells and tissue.

NBS is currently funding a project to study the feasibility of providing aqueous conductance standards as SRMs. This is essentially a start-up effort to explore needs and capabilities, after years of inactivity in this field of research at NBS. The needs of the scientific and industrial community will best be met through NBS participation and research, and through the issuance of a set of SRMs for electrolytic conductance. 


\section{RESPONSE TO SECTION $2 F$ \\ PHYSICAL/MECHANICAL MEASUREMENT REQUIREMENTS}

The material included in this section of NBS' Response is supplemental to that already included in the NCSL Report.

\section{SHOCK MEASUREMENT}

NBS Contact: Myroslav R. Serbyn (301) 921-3607

The NCSL Report confirms our conclusion that there is a need for a shock calibration service to fill the void left when the former NBS shock calibration service was terminated in 1975. We are in the process of reestablishing the shock calibration facility. Our shock-test machine has been factory overhauled during the past year and space for its installation has been obtained. It is expected that it will be installed and operating before the end of this year. Initially the service provided will be on a comparison basis, but if funds permit, this will ultimately be upgraded to an absolute service.

\section{Requirement}

Calibration of shock accelerometers using comparison methods to $30,000 \mathrm{~g}^{\prime} \mathrm{s}$ with an certainty of $1 \%$ to $5 \%$ and to $10,000 \mathrm{~g}^{\prime} \mathrm{s}$ with an uncertainty of $5 \%$ to $10 \%$.
Current NBS Capability

None

\section{HUMIDITY (HYGROMETRY) STANDARDS}

NBS Contact: Saburo Hasegawa (301) 921-2794

No new requirements were identified, but one respondent requested that existing services be continued. Our present services for humidity measurement devices are being automated to improve turnaround time.

\section{PARTICLE SIZE STANDARDS}

NBS Contact: Lee J. Kieffer (301) 921-2536

The NCSL Report confirms our conclusions that there is a need for particle-size Standard Reference Materials. The NBS Office of Standard Reference Materials has two new particle SRMs (0.3- $\mu \mathrm{m}$ and $0.9-\mu \mathrm{m}$ spheres) that are available and will soon start work on $3-\mu \mathrm{m}$ and $10-\mu \mathrm{m}$ spheres.

\section{$\underline{\text { Requirement }}$}

Spherical particle SRMs having 0.5 to $1.0 \mu \mathrm{m}$ diameters with uncertainty of $5 \%$.
Current NBS Capability

SRMs now available for spherical particles of nominal diameter of 0.3 and $0.9 \mu \mathrm{m}$ with uncertainty of $1 \%$.

\section{Plans and Comments}

Plans are to prepare a series of polystyrene spheres having diameters of $0.1,0.3,0.9,3,10$, and $30 \mu \mathrm{m}$. 
NBS Contact: James R. Whetstone (301) 921-3681

No new requirements were identified, but one respondent requested that existing services be continued. NBS plans to maintain the currently offered calibration services for hydrometers. To support new technology in the measurement of liquid density, Standard Reference Materials are planned. These will provide a direct tie to the unit of density as embodied in the single-crystal silicon density standards maintained by NBS.

\section{DIMENSIONAL MEASUREMENT}

NBS Contact: James R. Shaver (301) 921-2983

Our goal is to structure the Dimensional Metrology Program to handle the broad range of industrial needs, both now and in the long term. Specifically, we plan to maintain calibration services for manual artifacts such as gage blocks, spheres, and cylindrical standards. We also plan to maintain our support to the gaging community through the calibration of thread gages, plug gages, etc.

Our long term plan is to gradually reduce the number of such calibrations, allowing them to be done by secondary laboratories. Our current priority with respect to coordinate measuring machines is towards the adoption of the B89.1.12 Interim Standard as a National Standard, thus providing a traceability chain to NBS through the use of laser wavelengths or simple calibrated artifact standards such as step gages. In this way we seek to avoid calibrating large numbers of large, heavy, difficult to maneuver gages such as ball and hole plates. We intend to continue to offer one-of-a-kind special tests for these artifact standards should they be required by a particular organization.

The major priority of our program is to develop the new technology which we believe will be necessary for metrology in the factory of the future. That is, metrology techniques that control the dimensions of the part during the time it is, being manufactured. We call this approach "Deterministic Metrology", and the major thrust of the program is the characterization of machine tools, tooling, thermal and other errors that lead to incorrect parts, and sensors for monitoring such errors. This approach involves ensuring that quality assurance is built into the manufacturing process rather than focussed on inspection after the part is manufactured.

The only specific comment in the NCSL Report that dealt with Dimensional Metrology concerned coordinate measuring machines. We do have an extensive program in coordinate measuring machines, and we will continue to support the development of this technology and the dissemination of information to users. Through the Office of Standard Reference Materials we have made available a socketed-ball-bar set (SRM 2083) which can be used to determine the performance of a coordinate measuring machine in accordance with ASME Standard B89.1.12. We will also continue to develop the software supplied with such machines, including the computational algorithms for acquiring metrology information. We believe in the long run that the standardization of such algoritbms will lead to more accurate measurements. 
NBS has conducted a research project on the development of diamond pyramid hardness standards and now currently offers two SRMs through the Office of Standard Reference Materials. These are in the nominal ranges of 125 KHM (SRM 1894) and 550 KHM (SRM 1895) and will be certified both for Vickers and Knoop hardness at three commonly used loads of 25, 50 and $100 \mathrm{gf}$. The accuracy of the SRMs are certified at $\pm 5 \%$ and information is supplied to the purchaser to allow use at other loads.

Presently research is underway to develop additional diamond pyramid hardness standards at ranges of $60 \mathrm{KHM}, 800 \mathrm{KHM}$, and $1200 \mathrm{KHM}$. All of these standards have had all of the individual components which are involved with their certification calibrated against NBS fundamental standards of mass and length. Their surface finish is standardized and the measurements carried out in accordance with the appropriate ASTM recommended practice.

The need of industry for uniform diamond pyramid hardness standards has been widely known and documented. However, it remains unclear the extent to which industry requires NBS certified Rockwell standards. If Rockwell standards were necessary, electroforming techniques similar to those currently used with the diamond hardness SRMs could be used to fabricate the Rockwell standards, however, cast alloys may be more economical and serve just as well. This processing technology results in an extremely uniform material.

\section{AUTOCOLLIMATOR MEASUREMENT}

NBS Contact: William Gallagher (301) 921-2216

One respondent requested the calibration of an autocollimator with 10 minute nominal range and $0.1 \mathrm{sec}$ and of arc accuracy. While turnaround times for this service are longer than we would like, this service is readily available from NBS. 
EDUCATIONAL SEMINARS AND WORKSHOPS

NBS Contact: R. Keith Kirby (301) 921-2805

\section{REQUIREMENT:}

The NCSL national measurements requirements survey states: "One of the requirements common to most of the data packages and common to most of the respondent laboratories is the need for educational seminars and workshops along with technical information. There is a continuing need for these extremely important services in order to maintain well qualified and knowledgeable personnel in our laboratories. There is no more authoritative source for personnel. working with primary standards to obtain this type of training and information than through the NBS."

\section{NBS SEMINARS AND WORKSHOPS}

\section{SEMINAR ON DIGITAL METHODS IN WAVEFORM METROLOGY}

October, 1983 at NBS Gaithersburg

Contact: Barry A. Bell (301) 921-2727

This two-day seminar on Digital Methods in Waveform Metrology incorporated a program of lectures and laboratory demonstrations by NBS staff and discussion sessions. The seminar was intended to familiarize technicians, engineers, and scientists with the fundamental principles relating to precision waveform metrology in the dc-to-10 MHz regime, and to acquaint the attendees with the specific metrology program being carried out at NBS. The program was divided into presentations on precision waveform synthesis (digital waveform synthesis techniques, phase angle standards and calibration methods); precision waveform sampling (characterization of waveform recorders, dual-channel sampling systems); data converter characterization

(static/dynamic data converter testing, settling-time measurements); and instrumentation metrology (automatic thermal voltage converter calibrations, conductance measurements of gallium arsenide switches, automatic test equipment performance measurements and standards, conducted EMI effects on test equipment). Future similar seminars are planned.

WORKSHOP ON LASER BEAM PROFILE MEASUREMENTS

March 20, 1984 at NBS Boulder

Contact: Eric G. Johnson (303) 497-3234

This one day workshop will be held to identify problems in laser beam profile measurements, to discuss what NBS can do to help solve these problems, and the decide on the future role of NBS.

PRECISION THERMOMETRY SEMINAR

March 19-23 and October 15-19, 1984 at NBS Gaithersburg

Contact: Robert J. Soulen (301) 921-3316

This seminar will consist of integrated instruction in Platinum Resistance Thermometry, Liquid-in-Glass Thermometry, Thermocouple Thermometry, and Thermistor Thermometry to be given over a five day period. Material to be covered includes the International Practical Temperature Scale of 1968; its use in the laboratory; thermometers and instrumentation, including automatic 
data acquisition; the treatment of calibration data; and innovations in thermometry. Time will be split between lecture sessions and hands-on measurements in the laboratory. The seminar is especially intended for calibration laboratory personnel and others who wish to undertake precision temperature measurements.

\section{SEMINAR ON ELECTRICAL MEASUREMENT ASSURANCE PROGRAMS} March 26-30, 1984 in Dallas Contact: Arthur 0. McCoubrey (301) 921-3301

This five-day intensive seminar on measurement quality assurance provides in-depth training for those involved in dc and low frequency electrical measurements. Participants will receive instruction on how to establish and maintain rigorous quality control programs in their own laboratories to ensure the accuracy of electrical measurements. The primary emphasis will be on quality control for dc voltage metrology; the techniques used are readily applicable to other electrical measurement areas.

\section{SEMINAR ON ELECTROMAGNETIC NOISE MEASUREMENT}

April 30-May 4, 1984 at NBS Boulder

Contact: Ramon C. Baird (303) 497-3301

This seminar is intended for practicing noise metrologists and technical managers responsible for antenna and communication systems where accurate noise measurements are important. Sessions will address the accurate measurement of noise power, amplifier noise, and antenna system noise such as noise equivalent flux and $G / T$. Practical and theoretical aspects of precision noise measurement will be presented.

\section{CALIBRATION AND USE OF CONTROLLED-CLEARANCE PISTON GAGES}

April 2-6, 1984 at NBS Gaithersburg

Contact: Joanne Packard (301) 921-2121

This course will cover the theoretical and practical aspects of the calibration and use of controlled-clearance piston gages. Particular emphasis will be placed on the 100,000 psi Harwood gage. It will include lecture seminars, laboratory demonstrations, and hands-on experience. Emphasis will be placed on the acquisition and analysis of data required for the characterization of the gage as a primary standard. Attendance will be limited and participants will be split into smaller groups to facilitate use of the equipment and opportunities for individual questions.

The agenda will include:

Theory of controlled-clearance gas

Acquisition of fall-rate data

Crossfloating to determine effect of jacket pressure on area Analysis of laboratory data

Error estimation 
This seminar is intended for engineers and standards lab technicians involved in frequency calibrations. The course will be taught at a practical level to satisfy those new to the field as well as more experienced users. Methods taught will use commercially-available equipment. Topics to be covered:

Crystal Oscillator Calibration Applications of Frequency Counters

How to Choose a Frequency Calibration

Care and Use of Frequency Sources

Using Loran-C and WWBV for Frequency Calibrations

Time and Frequency Measurement Assurance Services at NBS

Organization of Time \& Frequency in the U.S.

NBS, USNO, and Other Publications

SEMINAR ON QUALITY ASSURANCE OF CHEMICAL MEASUREMENTS May 2-3 and 9-10, 1984 at NBS Gaithersburg

Contact: John K. Taylor (301) 921-3497

This two-day seminar is concerned with techniques to improve the precision and accuracy of analytical measurements such as those needed in the compositional analysis of materials, process control, and regulatory enforcement. It is designed for supervisors of analytical laboratories, experienced analytical chemists, and those responsible for the development andior supervision of laboratory quality control programs. Topics discussed will include: general aspects of quality assurance; the role of Standard Reference Materials in quality assurance; statistical considerations used in the evaluation of data quality; good laboratory practices for precise and accurate chemical measurements.

SEMINAR ON THE CALIBRATION AND USE OF PISTON GAGES May 17-18 and November 15-16, 1984 at NBS Gaithersburg Contact: Bernard E. Welch (301) 921-2121

This seminar is held to help industrial and other users attain the highest possible accuracy in pressure measurements with piston gages. The seminar is directed at engineers and senior technicians. The two-day seminar presents information on the theory of piston gages, elastic distortion, design and types, calibration of controlled clearance piston gages, calibration by cross-float, error analysis, computer programs, demonstration of cross-float, hydrostatic weighing and transducer calibrations.

SEMINAR ON FREQUENCY STANDARDS AND CLOCKS August, 1984 at NBS Boulder Contact: Mike Lombardi (303) 497-3212

This seminar is intended for program managers, planners, and systems engineers. Topics to be covered: 
A History of Time Scales

National and International Structure of Time \& Frequency

Concepts, Definitions, and Measures of Short-Term Frequency Stability

Techniques for Measuring Short-Term Frequency Stability and Noise in Oscillators

Review of Performance of Commercial Frequency Standards

Limitations of Present-Day Atomic Frequency Standards

Possible Advances in Future Clocks and Frequency Standards

The Process of Timekeeping (Clocks Modeling)

Time Coordination: Methods for Comparison of Time Scales

Propagation Effects on Radio Transmissions

Optical Techniques and Propagation Effects

SYMPOSIUM ON OPTICAL FIBER MEASUREMENTS

October 2-3, 1984 at NBS Boulder

Contact: Douglas L. Franzen (303) 497-3346

This symposium will provide a forum for reporting the results of current research and an opportunity for discussion that can lead to further progress on experimental or analytical aspects of the characterization of optical fibers and fiber optics systems, including attenuation, bandwidth/distortion, dispersion, index profile, cut-off wavelength, mode diameter/core geometry, fiber device (e.g., joint, coupler, multiplexer, etc.) evaluation, physical measurements, link parameters (e.g., concatenation), polarization characteristics, system performance, field measurements, and standards.

WORKSHOP ON MEASUREMENT OF GAGE BLOCKS

Held every few years at NBS Gaithersburg

Contact: Theodore D. Doiron (301) 921-2216

There are no current regularly scheduled training programs in gage block metrology, however every few years on customer demand a one-week workshop is offered. Those interested in participating in such a workshop should contact the Dimensional Metrology Group.

\section{LINEWIDTH TRAINING SEMINAR}

This seminar has been held about twice a year at various locations Contact: Diana Nyyssonen (301) 921-3786

This seminar is primarily intended to transfer NBS linewidth measurement technology to users in industry. Participants receive instruction in the basic workings of the optical microscope and the NBS-recommended linewidth measurement procedures.

Lectures, discussion, and equipment demonstrations cover state-of-the-art theory of optical measurement equipment and edge detection for linewidths in the 0.5- to 10-micrometer range. Specifically treated are procedures for setting up and calibrating equipment and analysis of calibration data with emphasis on establishment of precision and uncertainty. Lectures and discussion also include problems associated with linewidth measurements made with the scanning electron microscope (SEM) and other electron-beam systems. 
NBS/ASTM SMMPOSIUM ON RADIATION THERMOMETRY

May 8, 1984 at NBS Gaithersburg

Contact: Kenneth G. Kreider (301) 921-3281

This symposium is sponsored by NBS and ASTM Committee E20, Temperature Measurement. Technical papers will be presented on principles of measurement, methods of calibration, industrial applications, and case studies and recent research developments, including optical fiber thermometry and gas temperature measurements in combustion systems.

\section{ACKNOWLEDGMENT}

The editors would like to thank the NBS staff members who contributed to this document. 
1. PUBLICATION OR REPORT NO. NBSIR $84-2847(R)$
2. Performing Organ. Report Nod 3. Publication Date

March 1984

4. TITLE AND SUBTITLE National Bureau of Standards Response to the 1982 National

Measurement Requirements Survey of the National Measurement Requirements

Committee, National Conference of Standards Laboratories.

NBS Response to the 1982 NCSL National Measurement Requirements Survey.

5. $\operatorname{AUTHOR}(S)$

6. PERFORMING ORGANIZATION (If joint or other than NBS, see instructions)

7. Contract/Grant No.

NATIONAL BUREAU OF STANDARDS

DEPARTMENT OF COMMERCE

WASHINGTON, D.C. 20234

8. Type of Report \& Period Covered

9. SPONSORING ORGANIZATION NAME AND COMPLETE ADDRESS (Street, City, State, ZIP)

10. SUPPLEMENTARY NOTES

[Document describes a computer program; SF-185, FIPS Software Summary, is attached.

11. ABSTRACT (A 200-word or less factual summary of most significant information. If document includes a significant bibliography or literature survey, mention it here)

This response of the National Bureau of Standards (NBS) to the 1982 National Measurement Requirements Survey Report published by the NCSL's National Measurement Requirements Committee in May 1983 contains detailed information on the measurement services presently available from NBS and our future plans for new and expanded services. The information contained in the Survey Report is extremely useful to NBS in evaluating the effectiveness of ongoing programs and for planning future programs. The Report is particularly important to NBS because of the large number of organizations that have responded and because of the detailed technical requirements identified in the report.

12. KEY WORDS (Six to twelve entries; alphabetical order; capitalize only proper names; and seporate key words by semicolons) Calibrations, NBS measurement services, standard reference materials

13. AVAILABILITY

[ Unlimited

x For Official Distribution. Do Not Release to NTIS

$\square$ Order From Superintendent of Documents, U.S. Government Printing Office, Washington, D.C. 20402.

Order From National Technical Information Service (NTIS), Springfield, VA. 2216I
14. NO. OF PRINTED PAGES

45

15. Price 

